\title{
Ladle Intelligent Re-scheduling Method in Steelmaking-Refining-Continuous Casting Production Process based on BP Neural Network Working Condition Estimation
}

\section{Wei Liu}

Shenyang Institute of Engineering

Xinfu Pang ( $\sim$ pangxf@sie.edu.cn )

Shenyang Institute of Engineering https://orcid.org/0000-0001-6981-596X

Haibo Li

Shenyang Institute of Engineering

Liangliang Sun

Shenyang Jianzhu University

\section{Research Article}

Keywords: steelmaking-continuous casting, re-scheduling, ladle, BP neural network, first-order rules learning, heuristic

Posted Date: June 7th, 2021

DOl: https://doi.org/10.21203/rs.3.rs-538541/v1

License: (c) (i) This work is licensed under a Creative Commons Attribution 4.0 International License. Read Full License

Version of Record: A version of this preprint was published at The International Journal of Advanced Manufacturing Technology on January 20th, 2022. See the published version at https://doi.org/10.1007/s00170-021-08327-1. 


\title{
Ladle Intelligent Re-scheduling Method in Steelmaking-Refining-Continuous Casting Production Process based on BP Neural Network Working Condition Estimation
}

\author{
Wei Liu ${ }^{1}$, Xifu Pang, ${ }^{1 *}$, Haibo $\mathrm{Li}^{1}$, Liangliang Sun ${ }^{2}$ \\ 1. School of Automation, Shenyang Institute of Engineering, Shenyang, China \\ 2. chool of Information, Shenyang Jianzhu University, Shenyang, China \\ Corresponding Author's Email: pangxf@sie.edu.cn
}

\begin{abstract}
The ladle re-scheduling of steelmaking and continuous casting production aims at continuously casting many charges with the same cast and avoiding conflicts of adjacent charges on the same machine. It proposes a method of ladle re-scheduling in the production process of steelmaking-refining-continuous casting, including two parts: plan re-scheduling and ladle optimisation scheduling. Firstly, a re-scheduling optimisation model of the steelmaking and continuous casting production is built, which aims at minimising the waiting time of all charges. The re-scheduling strategy of steelmaking and continuous casting production is proposed by interval processing time of charges and scheduling expert experience. The re-scheduling strategy is composed of two parts: re-scheduling charge decision and charge processing machine decision. Then, the first-order rule learning is used to select the optimisation target to establish the ladle optimal scheduling model. The ladle matching rules are extracted by the rule reasoning of the minimum general generalisation. The ladle optimisation scheduling method consisting of the optimal selection of the ladle and the preparation of the optimal path of the ladle is proposed. Ladle selection is based on the production process and adopts rule-based reasoning to select decarburised ladle after choosing dephosphorised ladle. Ladle path preparation, a multi-priority heuristic method, is designed to decide the path of the ladle from the converter to the refining furnace to the continuous casting machine. Finally, it was actually verified based on a large-scale steel company in Shanghai, China. Results showed that the production efficiency of steelmaking-refining-continuous casting was improved.
\end{abstract}

Keywords: steelmaking-continuous casting; re-scheduling; ladle; BP neural network; first-order rules learning; heuristic

Declarations

Consent to Participate: Not applicable

Consent to Publish: Not applicable

Funding: Not applicable

Competing Interests: Not applicable

Availability of data and materials: Not applicable

Authors Contributions:

Wei Liu: Development or design of methodology; creation of models. Programming, software development; designing computer programs; implementation of the computer code and supporting algorithms; testing of existing code components. Application of statistical, mathematical, computational, or other formal techniques to analyze or synthesize study data.

Xinfu Pang: Conducting a research and investigation process, specifically performing the experiments, or data/evidence collection. Management activities to annotate (produce metadata), scrub data and maintain research data (including software code, where it is necessary for interpreting the data itself) for initial use and later reuse

Haibo Li: Preparation, creation and/or presentation of the published work, specifically visualization/ data presentation. Oversight and leadership responsibility for the research activity planning and execution, including mentorship external to the core team.

Liangliang Sun: Management and coordination responsibility for the research activity planning and execution. Acquisition of the financial support for the project leading to this publication.

\section{Introduction}

Modern steelmaking and continuous casting production are composed of multiple converters, refining furnaces and tundishes (the container for holding molten steel; the capacity is approximately 1/3 of the capacity of the ladle), continuous casting machines and steel ladles [1,2]. The molten steel is firstly poured into a transfer ladle after being processed on the converter. The molten steel in the same converter is called a charge. Thereafter, the charge of molten steel is transported by a crane to a refining furnace. The molten steel undergoes various refining processes at the refining stage. Finally, the molten steel is transported by a crane to a caster (a set of charges incessantly drained into a tundish of a continuous caster and solidifies in a crystalliser is called a cast).

The research in this paper is based on a large-scale steel company in Shanghai, China. The main equipment resources for the steelmaking-continuous casting process are shown in Figure 1. 
The steelmaking plant is the most complicated steel production process of its kind compared with Italian Steel [3], Sha Steel, Panzhihua Steel and Qianan Steel [4]. (1) Smelting is divided into single smelting (the converter only has decarburisation) or double smelting (firstly dephosphorises and then decarbonises), refining (one furnace is processed on one or more refining furnaces, called single or multiple refining, respectively) including 1-4 refining (the equipment has four types, namely, RH, LF, IR-UT and CAS); (2) The ladle matching needs to consider multiple constraints; (3) The precise transportation time needs to be determined by the ladle path and transportation equipment scheduling. The corresponding production equipment includes the converter, ladle refining furnace and continuous casting machine, of which the converter and continuous casting machine are fixed. The ladle refining furnace consists of two parts of equipment, one part is the ladle (mobile) that holds molten steel, and the other part is the furnace cover, heating electrode, vacuum tank and other equipment (fixed). The transportation equipment includes cranes and trolleys. The production scheduling is an optimisation problem of integrated production batch scheduling, selection of loading equipment and transportation equipment scheduling. Steelmaking-continuous casting production in a dynamic environment also has multiple disturbance characteristics.

In previous studies on steelmaking-continuous casting production systems, researchers used artificially estimated transportation time as known conditions. The selection of the ladle of the heat is not regarded as the decision-making quantity (the ladle is a part of the ladle refining furnace, which is equivalent to the refining equipment of the processing heat that is not fully arranged), and the static scheduling problem of the production equipment is studied [5]. The field test found that: the time disturbance is more than $80 \%$, and the production equipment cannot be accurately scheduled. The main reason is that the refining equipment for processing heat has not been fully arranged (lack of ladle options), and the transportation route has not been considered. Therefore, the problem of ladle re-scheduling must be studied based on the actual needs, which has an important theoretical value and practical significance.

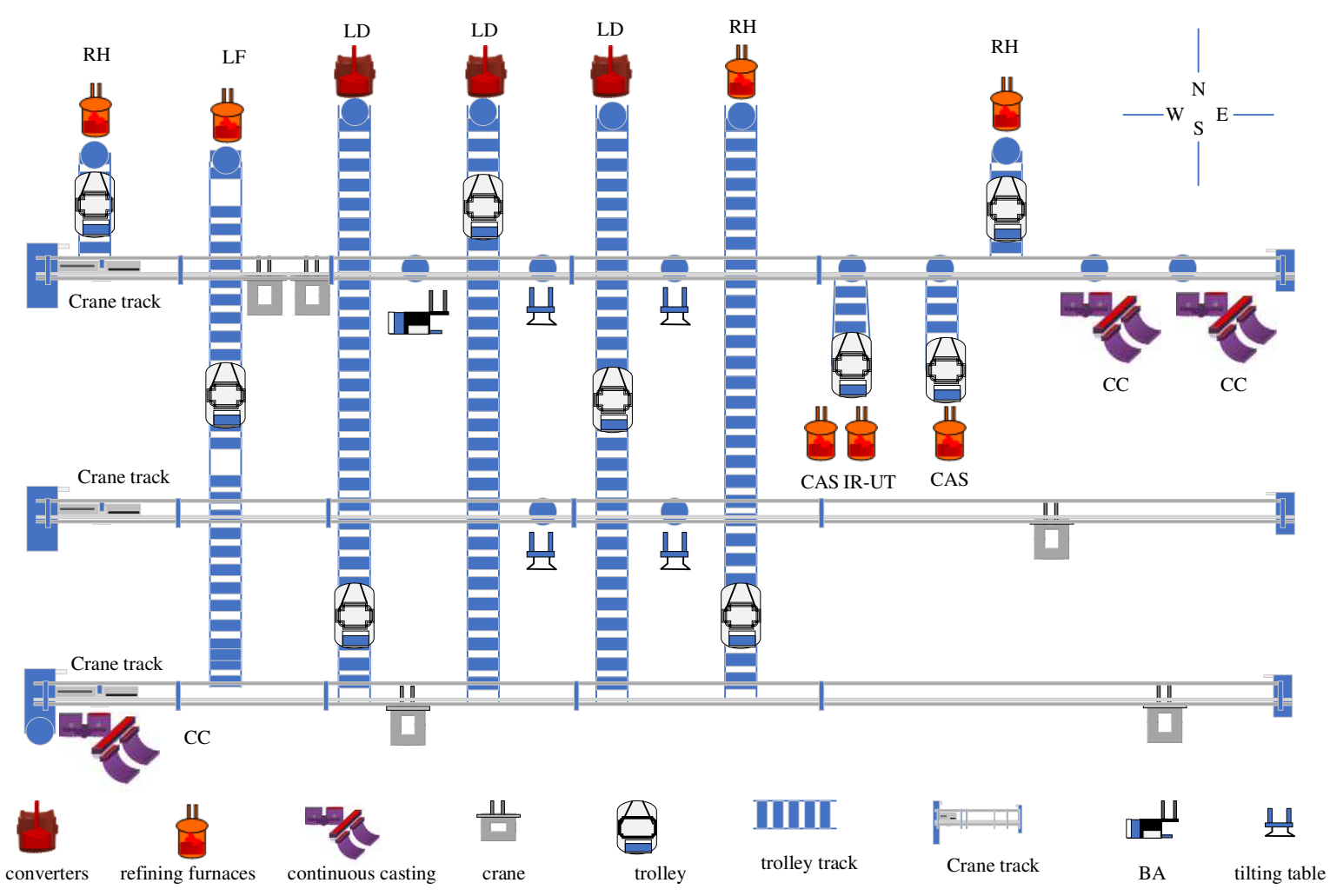

Figure. 1 Layout of the steelmaking plant

\section{Research status of steelmaking-continuous casting ladle re-scheduling}

In steelmaking and continuous casting production processes, the starting time delay frequently occurs, which may lead to casting break or processing conflict. Accordingly, the static scheduling plan becomes unrealisable. The requirements of the processing equipment (converter, refining furnace and continuous casting machine) of the heat are met according to the production equipment scheduling plan of the heat. Under the conditions of the start and end times of the equipment, a ladle carrying molten steel is selected, and the route of transporting the 
ladle is determined. Existing optimal scheduling methods are difficult to adopt because ladle re-scheduling must meet multiple conflicting goals and conflicting constraints.

Ladle is the equipment for loading molten steel, and it serves all the processing stages in the steelmakingcontinuous casting production. This equipment runs through the whole process from converter tapping, refining and continuous casting machine to casting billet formation. In the ladle of steelmaking-continuous casting process research, the researchers pay more attention to the structure and material of the ladle to reduce the heat loss during the service. The ladle, a part of the refining equipment outside the furnace, needs to solve two other problems: (1) the ladle matching and (2) the transportation scheduling problem. Otherwise, the refining process cannot be normally carried out according to the production equipment scheduling plan.

A three-step heuristic algorithm based on model features for ladle scheduling was proposed [6]. A multiobjective soft scheduling (MOSS) to overcome the uncertain scheduling problem arising from the steelmakingcontinuous casting (SCC) manufacturing system and proposes [7]. The steel plant continuous casting process computerised scheduling model was introduced [8]. A steel ladle scheduling system integrated system was established [9]. The impact of ladle on steelmaking scheduling was analysed [10]. The operation of ladle and calculated the number of ladles was considered reasonably [11].

The researcher abstracted the steelmaking-continuous casting production scheduling by using constraint satisfaction methods to re-scheduling equipment failures and quality disturbance [12]. The utility function and stability were used to judge the rescheduling result [13]. a multi-stage dynamic soft scheduling (MDSS) algorithm based on an improved differential evolution was proposed [14].

The main focuses of the literature on ladle management, with an emphasis on ladle turnover, are to simplify the constraints related to ladle selection and study the simplified ladle production model. The actual production of optimal matching ladle needs is difficult to meet when the ladle matching complex constraints are not fully considered. How to carry out effective ladle re-scheduling is a problem that must be solved in every steel mill's workshop production scheduling. The study of ladle re-scheduling in steel mill workshops cannot be separated from static scheduling; it is the guarantee for good production scheduling to be implemented.

\section{Analysis of ladle scheduling problems}

The overall scheduling strategy of steelmaking-refining-continuous casting is shown in Figure 2. This Under the premise that the production process path and the heat treatment time are fixed constants, the steelmaking-continuous casting production static scheduling is based on the given pouring time on the continuous casting machine on time, continuous heat casting in the same pouring time and on the same equipment. The goal is to prevent conflict between adjacent heat. Then, the processing equipment of heat, the refining and the start time of heat in the converter, refining furnace and continuous casting machine are decided, and a schedule is formed.

Re-scheduling is based on the original static scheduling plan. The processing status of the heat is known, and the production process path of the heat is known and unchanged. The processing and transportation times of the heat on the converter and refining furnace are known and unchanged. The performance indexes are two types of adjacent heat on the same equipment that do not produce operational conflicts. The heat within the casting cycle is continuously cast. Moreover, the processing time of heat on the continuous casting machine does not exceed the limited range.

Re-scheduling is conducted to determine the processing equipment and start time of the unprocessed heat in each cast. This process is also carried out to identify the start and end times of the unprocessed heat on the continuous caster and the end time of the processed heat on the continuous caster. Then, a new scheduling plan is formed.

The ladle matching directly affects the temperature and composition of heat. This condition indirectly affects the processing time of the heat and brings disturbance to the scheduling plan. Ladle matching is based on the steelmaking-refining-continuous scheduling plan and the state of the ladle. A suitable ladle is determined from the ladle used on site for each furnace. The ladle path is compiled for the heat to determine all the transportation sections used in the production. The transportation section is divided by the crane running track divided by whether the crane can put the ladle as the separation. Then, the ladle transportation route plan that meets the site requirements is determined.

If a satisfactory solution cannot be obtained, the processing time or equipment of the heat is adjusted through a human-computer interaction until a satisfactory solution is obtained.

In summary, the ladle re-scheduling problem is a large-scale combinatorial optimisation problem with multiple objectives and constraints. At present, steelmaking plants can only use manual or telephone methods to guide the dispatch of ladle. This situation leads to low efficiency in the execution of the scheduling plan, which can easily result in excessive furnace redundancy time and untimely ladle transportation. The temperature of the molten steel decreases, thus requiring additional heating, and punctual pouring is difficult to ensure.

This work considers multiple refining to meet the requirements of continuous casting and ladle production technology. A steelmaking-continuous casting ladle re-scheduling model is established on the basis of satisfying 
the process sequence, equipment capacity, pouring time, processing time and transportation time constraints. This work studies the algorithm for solving ladle re-scheduling in a dynamic environment, conducts ladle re-scheduling and revises the production equipment scheduling plan. The start and end processing times of the converter, refining, and ladle are optimised. An accurate production equipment re-scheduling plan is obtained, and ladle scheduling is carried out. Finally, this work is verified through actual industrial cases.

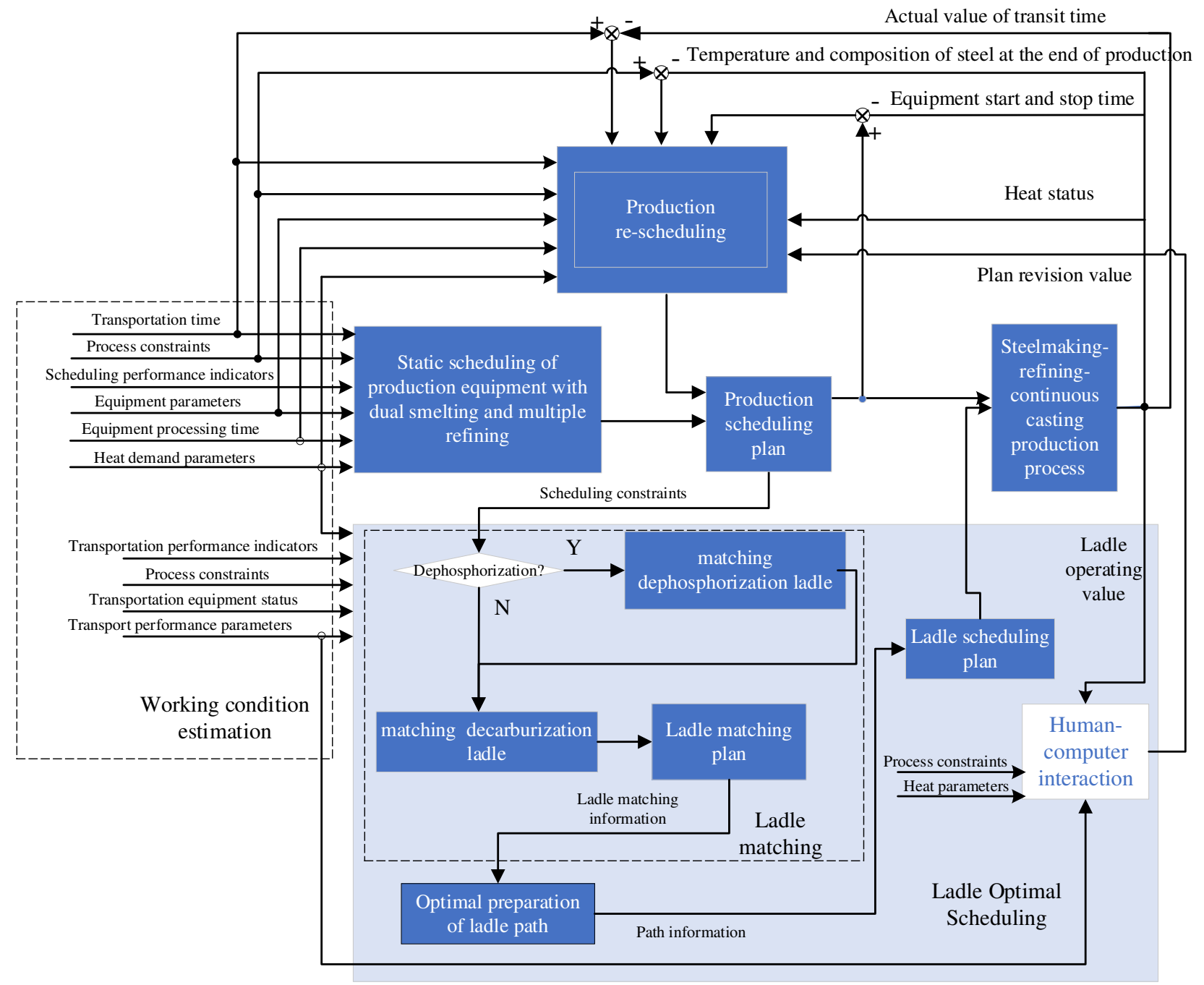

Figure. 2 Steelmaking-refining-continuous casting overall scheduling strategy diagram

\section{Modelling of the ladle re-scheduling problem}

The problem of ladle re-scheduling is divided into two parts: (1) ladle re-scheduling and (2) ladle optimisation scheduling. Firstly, the static plan is re-scheduling based on the actual production operation. On this basis, the ladle scheduling is optimised. These processes are described as follows.

\subsection{Re-scheduling adjustment modelling \\ 4.1.1 Symbol definition}

Index:

$i \quad$ Cast serial number

$j \quad$ Heat serial number

$g \quad$ Device type number

$k_{g} \quad k$ th device of type $g$

$m_{g b} \quad b$ th device of device type $g$

$\Omega_{i} \quad$ The heat that has not been started in the continuous casting stage in the $i$ th cast is set.

Parameter:
$N \quad$ Total number of cast
$J_{i} \quad$ Total heat number of cast $i$
$L_{i j} \quad j$ th heat of cast $i$ 


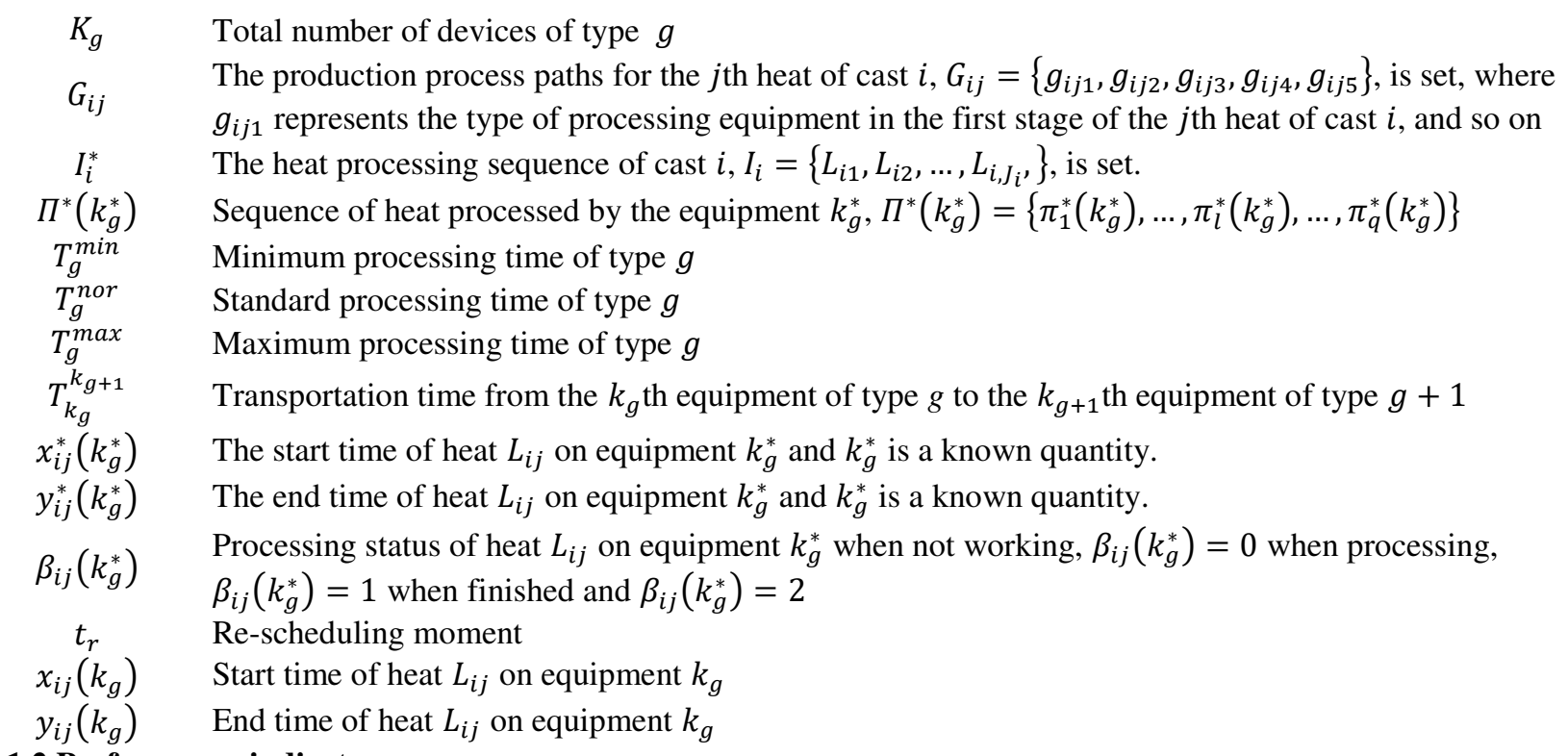

\subsubsection{Performance indicators}

The temperature of molten steel in the ladle is one of the process parameters that need to be controlled in the steelmaking process. If the temperature of the molten steel is low, then the processing time of the molten steel on the refining equipment must be extended, or other refining equipment for heating treatment must be added. This approach will increase the production cycle and seriously affect production. Therefore, the interval time between each process in the production must be strictly controlled. Specifically, the total waiting time of the heat between adjacent processing equipment must be as small as possible.

The difference between the start time $x_{i j}\left(k_{g}\right)$ and the completion time $y_{i j}\left(k_{g-1}\right)$ and the transportation time between equipment $T_{k_{g-1}}^{k_{g}}, x_{i j}\left(k_{g}\right)-y_{i j}\left(k_{g-1}\right)-T_{k_{g-1}}^{k_{g}}$, which is the processing waiting time $W_{i j}\left(k_{g}\right)$ of $L_{i j}$ between stages $g-1$ and $g$ :

$$
W_{i j}\left(k_{g}\right)=x_{i j}\left(k_{g}\right)-y_{i j}\left(k_{g-1}\right)-T_{k_{g-1}}^{k_{g}} \quad i=1, \ldots, N ; L_{i j} \in \Omega_{i} ; g=2, \ldots, 5
$$

The sum of the processing waiting time $W_{i j}$ of the heat $L_{i j}$ in all adjacent processes is obtained as follows:

$$
W_{i j}=\sum_{g=2}^{5} W_{i j}\left(k_{g}\right)=\sum_{g=2}^{5}\left(x_{i j}\left(k_{g}\right)-y_{i j}\left(k_{g-1}\right)-T_{k_{g-1}}^{k_{g}}\right) \quad i=1, \ldots, N ; L_{i j} \in \Omega_{i}
$$

Therefore, the total processing waiting time $W$ of heat in the adjacent processes is $W=\sum_{i=1}^{N} \sum_{L_{i j} \in \Omega_{i}} W_{i j}$. The optimisation goal is to minimise $W$, that is, to establish the following performance indicators:

\subsubsection{Constraints}

$$
\begin{gathered}
\text { Min } W=\sum_{i=1}^{N} \sum_{L_{i j} \in \Omega_{i}} W_{i j}=\sum_{i=1}^{N} \sum_{L_{i j} \in \Omega_{i}} \sum_{g=2}^{5} W_{i j}\left(k_{g}\right) \\
=\sum_{i=1}^{N} \sum_{L_{i j} \in \Omega_{i}} \sum_{g=2}^{5}\left(x_{i j}\left(k_{g}\right)-y_{i j}\left(k_{g-1}\right)-T_{k_{g-1}}^{k_{g}}\right)
\end{gathered}
$$

(1) The heat in the same casting must follow the casting order.

$x_{i, j+1}\left(k_{5}\right)$ must be equal to $y_{i j}\left(k_{5}\right)$ as much as possible to make continuous casting of adjacent heat $L_{i j}$ and $L_{i, j+1}$ in the same cast, namely,

$$
x_{i, j+1}\left(k_{5}\right)-y_{i j}\left(k_{5}\right)=0 \quad i=1,2,3 ; j=1, \ldots, J_{i}-1
$$

because the processing time of heat $L_{i j}$ on the continuous caster is within a range of $\left[T_{5}^{\min }, T_{5}^{\max }\right]$, namely:

$$
\begin{aligned}
& y_{i j}\left(k_{5}\right)-x_{i j}\left(k_{5}\right) \leq T_{5}^{\max } \\
& \quad y_{i j}\left(k_{5}\right)-x_{i j}\left(k_{5}\right) \geq T_{5}^{\min }
\end{aligned}
$$

When the starting time interval $x_{i, j+1}\left(k_{5}\right)-x_{i j}\left(k_{5}\right)$ of heat $L_{i j}$ and $L_{i, j+1}$ is less than or equal to the maximum processing time $T_{5}^{\max }$ :

$$
x_{i, j+1}\left(k_{5}\right)-x_{i j}\left(k_{5}\right) \leq T_{5}^{\max }
$$

(2) Heat processing sequence constraint: each stage of heat processing must be processed in sequence according to the order specified by the production process.

To ensure that the heat is processed in the order specified by the production process path, heat $L_{i j}$ can be processed at stage $g+1$ only when $L_{i j}$ is completed in stage $g$ and reaches stage $g+1$ after being transported. Specifically, $x_{i j}\left(k_{g+1}\right)-y_{i j}\left(k_{g}\right)-T_{k_{g}}^{k_{g+1}}$ must be greater than or equal to zero, namely: 


$$
x_{i j}\left(k_{g+1}\right)-y_{i j}\left(k_{g}\right)-T_{k_{g}}^{k_{g+1}} \geq 0 \quad i=1,2,3 ; j=1, \ldots, J_{i} ; g=1, \ldots,\left|G_{i j}\right|-1
$$

(3) Conflict constraints that cannot occur between different heat processed on the same equipment

Heat operating conflict means that two heat simultaneously occupy the same equipment resource. The six types of on-site work time conflicts are as follows (Figure 3):

A. Front cross conflict: The newly-arranged heat is operated before the scheduled heat, and the operation time of the two is partially overlapped, as shown in Figure 3 (a);

B. Post-cross conflict: The newly heat is operated after the scheduled heat, and the operation time of the two partially overlaps, as shown in Figure 3 (b);

C. Contain conflict: the newly-arranged heat is operated after the arranged heat, and the operation time overlaps, as shown in Figure 3 (c);

D. Outside containing conflict: the newly-arranged heat is operated before the scheduled heat, and the operation time overlaps, as shown in Figure 3 (d);

E. Complete conflict: The operation time of the newly arranged heat completely overlaps, as shown in Figure $3(\mathrm{e})$

F. Mixed conflict: The operation time of the heat and the two scheduled heat have post-cross and front cross conflicts, as shown in Figure 3 (f).

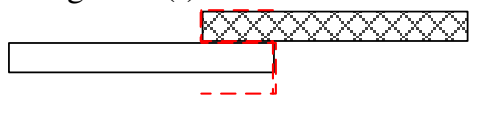

(a) Front cross conflict

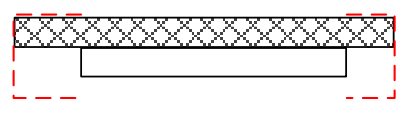

(c) Contain conflict

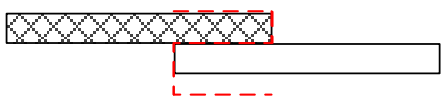

(b) Post-cross conflict

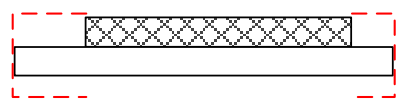

(d) Outside containing conflict

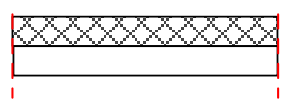

(e) Complete conflict

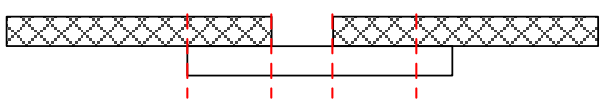

(f) Mixed conflict

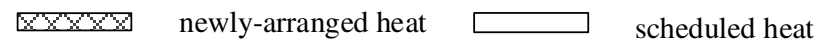

Figure. 3 Classification of time conflict amongst charges

According to whether the heat processing equipment is known, the number of process processing equipment is different and combined with the on-site situation. The three situations for analysis of heat operating conflicts between different heat processed on the same equipment are as follows:

I. Adjacent heat on the same continuous casting machine cannot produce operating time conflicts

The heat immediately after heat $L_{i j}$ on the continuous casting machine is $L_{i, j+1}$. When $\mathrm{t} x_{i, j+1}\left(k_{5}\right)-$ $y_{i j}\left(k_{5}\right) \geq 0$, heat $L_{i, j+1}$ and $L_{i j}$ will not conflict. Thus:

$$
x_{i, j+1}\left(k_{5}\right)-y_{i j}\left(k_{5}\right) \geq 0 \quad i=1,2,3 ; j=1, \ldots, J_{i}-1
$$

II. In any type of equipment, only one equipment (IR_UT) adjacent to the heat cannot produce the operation time conflict

Under the premise that the heat production process path is known, heat that needs to be processed by IR_UT can be obtained. Assuming that $\Omega_{I R_{-} U T}$ is the set of heat processed by IR_UT, and the amount of heat contained in it is $N_{I R_{-} U T}$. Given that IR_UT has only one device for the heat in $N_{I R_{-} U T}$, its start and completion times on IR_UT can be expressed as $x_{i j}\left(k_{4}\right)$ and $y_{i j}\left(k_{4}\right)$. In any two heat in $\Omega_{-}$(IR_UT) that cannot conflict, the description is as follows:

$$
\min \left(y_{i j}\left(k_{4}\right), y_{i_{1}, j_{1}}\left(k_{4}\right)\right)-\max \left(x_{i j}\left(k_{4}\right), x_{i_{1}, j_{1}}\left(k_{4}\right)\right) \leq 0 L_{i j}, L_{i_{1}, j_{1}} \in \Omega_{I R_{-} U T}, L_{i j} \neq L_{i_{1}, j_{1}}
$$
heat

III. On each equipment $(\mathrm{RH})$ with multiple parallel machines, no time conflict can be generated for adjacent

Under the premise that the heat production process path is known, heat that needs to be processed by RH can be obtained. This study assumes that $\Omega_{R H}$ is the set of all heat processed by $\mathrm{RH}$, and the number of heat it contains is $N_{R H}$. Only three RHs are present on site. The start and completion times on RH of the heat in $\Omega_{R H}$ can be expressed as $x_{i j}\left(k_{2}\right)$ and $y_{i j}\left(k_{2}\right)$, respectively. The description of any two heat in $\Omega_{R H}$ that cannot conflict is as follows:

$$
\begin{array}{r}
\min \left(y_{i j}\left(k_{2}\right), y_{i_{1}, j_{1}}\left(k_{2}\right)\right)-\max \left(x_{i j}\left(k_{2}\right), x_{i_{1}, j_{1}}\left(k_{2}\right)\right) \leq 0 \\
L_{i j}, L_{i_{1}, j_{1}} \in \Omega_{R H}, \text { and } L_{i j} \neq L_{i_{1}, j_{1}} ; k_{2}=1, \text { or } 2 \text {, or } 3
\end{array}
$$

(4) Constraint of processing time of the heat

The processing time meets:

$$
y_{i j}\left(k_{g}\right)-x_{i j}\left(k_{g}\right) \leq T_{g}^{\max }
$$




$$
y_{i j}\left(k_{g}\right)-x_{i j}\left(k_{g}\right) \geq T_{g}^{\min }
$$

(5) Constraint on the heat in the continuous casting process

During the entire re-scheduling, the continuous caster must be in the initial scheduling plan, namely:

$$
k_{\left|G_{i j}\right|}=m_{i, j,\left|G_{i j}\right|}^{0} \quad i=1,2,3 ; j=1, \ldots, J_{i}
$$

(6) Constraint on the casting sequence of the heat in the same cast

In a given casting schedule, the processing sequence of the heat in the same cast on the continuous caster is known, namely:

$$
x_{i, j+1}\left(k_{\left|G_{i, j+1}\right|}\right)-y_{i j}\left(k_{\left|G_{i j}\right|}\right) \geq 0 \quad i=1,2,3 ; j=1, \ldots, J_{i}
$$

(7) Constraint on processing equipment at each stage of the heat

A device type contains multiple devices with the same function. Heat can only be processed on one of the equipment in each stage, namely:

$$
k_{g}=\operatorname{ENUM}\left\{1, \ldots, K_{g} \mid x_{i j}\left(k_{g}\right)\right\} \quad i=1,2,3 ; j=1, \ldots, J_{i} ; g \in G_{i j}
$$

(8) Constraints on processing equipment, start-up time and completion time of heat in the process

When heat $L_{i j}$ has been processed in a certain stage $g\left(L_{i j}\right)$, the processing equipment, start time and completion time of heat $L_{i j}$ in stage $g$ cannot be changed, namely:

$$
\begin{array}{cc}
k_{g}=m_{i j}^{\#}\left(k_{g}\right) & i=1,2,3 ; j=1, \ldots, J_{i} ; g=1, \ldots,\left|G_{i j}\right| ; \beta_{i j}\left(k_{g}\right)=2 \\
x_{i j}\left(k_{g}\right)=x_{i j}^{\#}\left(k_{g}\right) & i=1,2,3 ; j=1, \ldots, J_{i} ; g=1, \ldots,\left|G_{i j}\right| ; \beta_{i j}\left(k_{g}\right)=2 \\
y_{i j}\left(k_{g}\right)=y_{i j}^{\#}\left(k_{g}\right) & i=1,2,3 ; j=1, \ldots, J_{i} ; g=1, \ldots,\left|G_{i j}\right| ; \beta_{i j}\left(k_{g}\right)=2
\end{array}
$$

(9) Constraint on the processing equipment and start-up time of the processing heat

When $L_{i j}$ is processing $\left(\beta_{i j}\left(k_{g}\right)=1\right)$, the processing equipment and start time cannot be changed, namely:

\subsubsection{Decision variables}

$$
\begin{gathered}
k_{g}=m_{i j}^{\#}\left(k_{g}\right) \quad i=1,2,3 ; j=1, \ldots, J_{i} ; g=1, \ldots,\left|G_{i j}\right| ; \beta_{i j}\left(k_{g}\right)=1 \\
x_{i j}\left(k_{g}\right)=x_{i j}^{\#}\left(k_{g}\right) \quad i=1,2,3 ; j=1, \ldots, J_{i} ; g=1, \ldots,\left|G_{i j}\right| ; \beta_{i j}\left(k_{g}\right)=1
\end{gathered}
$$

The content that needs to be adjusted when rescheduling includes: (1) the processing equipment, start time and completion time of heat in the unstarted process; (2) the completion time of the heat in the process. Therefore, the following decision variables are selected:

$x_{i j}\left(k_{g}\right)$, which is the time decision variable for re-scheduling. It is an integer variable and the start time of $L_{i j}$ on equipment $k_{g}$.

$y_{i j}\left(k_{g}\right)$, which is the time decision variable for re-scheduling. It is an integer variable and the end time of $L_{i j}$ on equipment $k_{g}$.

\subsection{Ladle optimal scheduling model}

\subsubsection{Optimisation target selection}

The first-order rule learning is used to learn the training set, ladle matching attribute set $A=$ $\left\{a_{1}, a_{2}, \cdots, a_{18}\right\}=\{$ Steel species, ladle number, $\ldots$, empty ladle weight $\}$ (Table 1).

Table 1 Definition of the ladle matching properties

\begin{tabular}{lcl}
\hline \multicolumn{1}{c}{ Attributes } & Symbol & \multicolumn{1}{c}{ Variable description } \\
\hline Steel species & $S k$ & Furnace number of the process \\
Ladle number & $k$ & Ladle serial number \\
Ladle bales regulation & $R_{m}$ & Ladle bales m-bit regulation \\
Ladle status & $S_{m}^{k}$ & $m$-bit ladle $k$ state \\
At the end of the cold steel volume & $R(k)$ & Ladle $k$ remaining molten steel \\
Ladle temperature & $T(k)$ & Temperature of ladle $k$ \\
Ladle material & $M(k)$ & Ladle $k$ material \\
Number of sewers & $D(k)$ & Number of ladle $k$ 's outlet \\
Usage count & $L(k)$ & Number of ladle $k$ to use \\
Supra number of use (East) & $U_{e}^{k}$ & Ladle $k$ east outlet number of uses \\
Number of uses of the outlet (West) & $U_{w}^{k}$ & Ladle $k$ West catchment use frequency \\
Skate usage (East) & $S_{e}^{k}$ & Ladle $k$ east skateboard use frequency \\
Number of skateboards (west) & $S_{w}^{k}$ & Ladle $k$ West slide use frequency \\
Drainage (East) & $M_{e}^{k}$ & Ladle $k$ drainage material (East) of the material \\
Drainage (West) & $M_{w}^{k}$ & Ladle $k$ drainage material (West) \\
Frame usage (East) & $F_{e}^{k}$ & Ladle $k$ frame (East) use frequency \\
\hline
\end{tabular}




\begin{tabular}{lcl}
\hline \multicolumn{1}{c}{ Attributes } & Symbol & \multicolumn{1}{c}{ Variable description } \\
\hline Frame usage (West) & $F_{w}^{k}$ & Ladle $k$ frame (West) for the number of uses \\
Empty ladle weight & $E(k)$ & Ladle $k$ empty ladle weight \\
\hline
\end{tabular}

The typical and random data are selected to build the ladle training set, in which the ratio of typical and random data is 1:3 (Table 2). The data conversion and the establishment of the relational data are shown in Table 3.

Table 2 Data set of ladle matching

\begin{tabular}{|c|c|c|c|c|c|c|c|c|c|c|}
\hline & $\begin{array}{c}\text { Steel } \\
\text { species }\end{array}$ & $\begin{array}{c}\text { Refin } \\
\text { ing }\end{array}$ & $\begin{array}{l}\text { Tempe } \\
\text { rature }\end{array}$ & $\begin{array}{c}\text { Ladle } \\
\text { material }\end{array}$ & $\begin{array}{l}\text { Ladle } \\
\text { status }\end{array}$ & $\cdots$ & $\begin{array}{c}\text { Drainage } \\
\text { material } \\
\text { (East) }\end{array}$ & $\begin{array}{c}\text { Drainage } \\
\text { material } \\
\text { (West) }\end{array}$ & $\begin{array}{c}\text { Empty } \\
\text { ladle } \\
\text { weight }\end{array}$ & $\begin{array}{l}\text { Avai } \\
\text { lable }\end{array}$ \\
\hline 1 & $\begin{array}{c}\text { AK20220 } \\
4\end{array}$ & $\mathrm{R}$ & $>1341$ & $\begin{array}{l}\text { Overall } \\
\text { ladle }\end{array}$ & Run & $\ldots$ & Forsterite & Forsterite & 136 & Can \\
\hline 2 & AP1055E5 & $\mathrm{R}$ & $>1126$ & $\begin{array}{l}\text { Magnesiu } \\
\mathrm{m} \\
\text { aluminium }\end{array}$ & $\begin{array}{c}\text { Preparat } \\
\text { ion }\end{array}$ & $\ldots$ & Silicon & Silicon & 125 & Can \\
\hline 3 & AP1055E5 & $\mathrm{R}$ & $>1457$ & $\begin{array}{l}\text { Aluminium } \\
\text { magnesium } \\
\text { carbon }\end{array}$ & Dry & $\ldots$ & Zirconium & Zirconium & 145 & No \\
\hline 4 & AP1055E5 & $\mathrm{R}$ & $>1600$ & $\begin{array}{l}\text { Overall } \\
\text { ladle }\end{array}$ & Repair & $\cdots$ & $\begin{array}{c}\text { Chromiu } \\
\mathrm{m}\end{array}$ & $\begin{array}{c}\text { Chromiu } \\
\mathrm{m}\end{array}$ & 142 & No \\
\hline 5 & AP1055E5 & $\mathrm{R}$ & $<879$ & $\begin{array}{l}\text { Magnesiu } \\
\mathrm{m} \\
\text { aluminium }\end{array}$ & Run & $\ldots$ & Forsterite & Forsterite & 128 & No \\
\hline 6 & $\begin{array}{c}\mathrm{XK} 43731 \\
1\end{array}$ & LR & $<1379$ & $\begin{array}{l}\text { Overall } \\
\text { ladle }\end{array}$ & $\begin{array}{c}\text { Preparat } \\
\text { ion }\end{array}$ & $\cdots$ & Forsterite & Forsterite & N/A & Can \\
\hline & $\ldots$ & $\ldots$ & $\ldots$ & $\ldots$ & $\ldots$ & $\ldots$ & $\ldots$ & $\ldots$ & $\ldots$ & $\ldots$ \\
\hline
\end{tabular}

Table 3 Data relationship of ladle matching

\begin{tabular}{|c|c|c|c|c|c|}
\hline \multirow[t]{2}{*}{$\begin{array}{l}\text { Background } \\
\text { knowledge }\end{array}$} & $\begin{array}{c}\text { Ladle } \\
\text { temperature is } \\
\text { higher }(1,2) \\
\text { Ladle } \\
\text { temperature is } \\
\text { higher }(3,1)\end{array}$ & $\begin{array}{l}\text { Ladle material is } \\
\text { higher }(1,2)\end{array}$ & $\begin{array}{l}\text { Ladle uses a higher } \\
\text { number of times } \\
(1.2) \\
\text { Ladle uses a higher } \\
\text { number of times } \\
(3.1)\end{array}$ & $\begin{array}{c}\text { The number of } \\
\text { sewer is higher } \\
\text { (1.2) } \\
\text { The number of } \\
\text { sewer is higher } \\
\text { (1.3) }\end{array}$ & $\cdots$ \\
\hline & $\ldots$ & $\ldots$ & $\ldots$ & $\ldots$ & $\ldots$ \\
\hline \multirow[t]{2}{*}{ Example } & $\begin{array}{c}\text { Better }(1,3) \\
\neg \text { Better }(3,1)\end{array}$ & $\begin{array}{c}\text { Better }(1,4) \\
\neg \text { Better }(4,1)\end{array}$ & $\begin{array}{c}\text { Better }(1,5) \\
\neg \text { Better }(5,1)\end{array}$ & $\begin{array}{c}\text { Better }(1,6) \\
\neg \text { Better }(6,1)\end{array}$ & $\begin{array}{l}\ldots \\
\ldots\end{array}$ \\
\hline & $\ldots$ & $\ldots$ & $\ldots$ & $\ldots$ & $\ldots$ \\
\hline
\end{tabular}

The atomic formula transformed from the sample analogy for ' $\neg$ better' and 'better' is called the relational data sample. Decarburisation ladle matching initial empty rule is applied using First-Order Inductive Learner (FOIL) for rule-based learning:

'FOIL Gain' is used to select the text:

$$
\operatorname{better}(X, Y) \leftarrow \text {. }
$$

$$
F_{\text {Gain }}=\widehat{m}_{+} \times\left(\log _{2} \frac{\widehat{m}_{+}}{\hat{m}_{+}+\hat{m}_{-}}-\log _{2} \frac{m_{+}}{m_{+}+\hat{m}_{-}}\right)
$$

where $\widehat{m}_{+}$and $\widehat{m}_{-}$are the positive and negative examples covered by the new rules after adding the candidate words; $\widehat{m}_{+}$and $\widehat{m}_{-}$are the number of positive and negative examples covered by the original rules. Based on field experts, we select the typical positive and negative samples to learn the minimum coverage of all the attributes of the sample as the optimal target of ladle matching.

\subsubsection{Ladle optimal scheduling model}

\section{A Performance indicator}

(1) Ladle temperature

(2) Number of ladle used

$$
\max T(k)
$$$$
\max \quad L(k)
$$

(3) Transport time

$$
\min \sum t r_{i j}\left(k_{g(\theta)}, k_{g(\theta+1)}\right)
$$


(4) Start work on time as much as possible

\section{B Constraints}

$$
\max \sum z_{i j \theta}^{k g}
$$

(1) Crane weight

The maximum load of the crane of path $k_{7}$ selected by heat $L_{i j}$ is greater than the weight of the molten steel of $L_{i j}$.

(2) Crane operating speed

$$
L o_{i j}<\operatorname{Lo}\left(k_{7}\right)
$$

The operating speed and distance of the crane shall not exceed the time requirements specified in the scheduling plan.

(3) Ladle temperature

$$
l\left(k_{7}\right) / v+2 d<\operatorname{tr}_{i j}\left(k_{g(\theta)}, k_{g(\theta+1)}\right)
$$

The temperature of the ladle cannot exceed the upper and lower limits of the process requirements.

(4) Crane position

$$
T_{\min }^{i j} \leq T(k) \leq T_{\max }^{i j}
$$

The crane $k_{g}$ runs within a unit of time to meet:

(5) Matching crane

$$
P_{k_{g}}^{t}+v \geq P_{k_{g}}^{t+1} \geq P_{k_{g}}^{t}-v
$$

Every $O_{j \theta}$ should be allocated to a crane. A crane can handle at most one transportation task.

(6) Transportation safety

$$
\sum y_{j \theta}^{k_{g}}=1, \quad \sum Y_{j \theta t}^{k_{g}} \leq 1
$$

The minimum distance between two adjacent cranes:

$$
\left|P_{k_{8}^{\prime}}^{t}-P_{k_{8}}^{t}\right| \geq \delta
$$

\section{Decision variables}

(1) A dephosphorisation ladle is chosen for each furnace $L_{i j}$ with dephosphorisation process

$$
\text { IF } G p_{i j}=1 \text { THEN } \exists ! L c_{i j, k}=1
$$

(2) A decarburisation ladle is chosen for each furnace $L_{i j}$

$$
\exists ! L c_{i j, k}=1
$$

\section{Ladle re-scheduling algorithm}

In view of the uncertain factors that often appear in the manufacturing process (transportation delays, processing overtime, and the need to adjust the plan for substandard quality, etc.), it is necessary to propose a corresponding rescheduling plan according to the working conditions. Generally, generating a re-scheduling plan requires changing the constraints in the scheduling model according to the current status of the workshop and recalculating. However, if some parameters (completion time, processing time, transportation time, etc.) are only set according to standard values, the modified plan will be rescheduled again. In order to reduce the number of rescheduling, this paper uses BP neural network to quickly estimate rescheduling algorithm parameters.

First, the neural network is trained according to the scheduling knowledge prepared by the manufacturing system. Then, when an uncertain event occurs, the current changed system state is used as the input of the trained neural network, and the expected rescheduling parameters are calculated through the BP neural network. As shown in Figure 4.

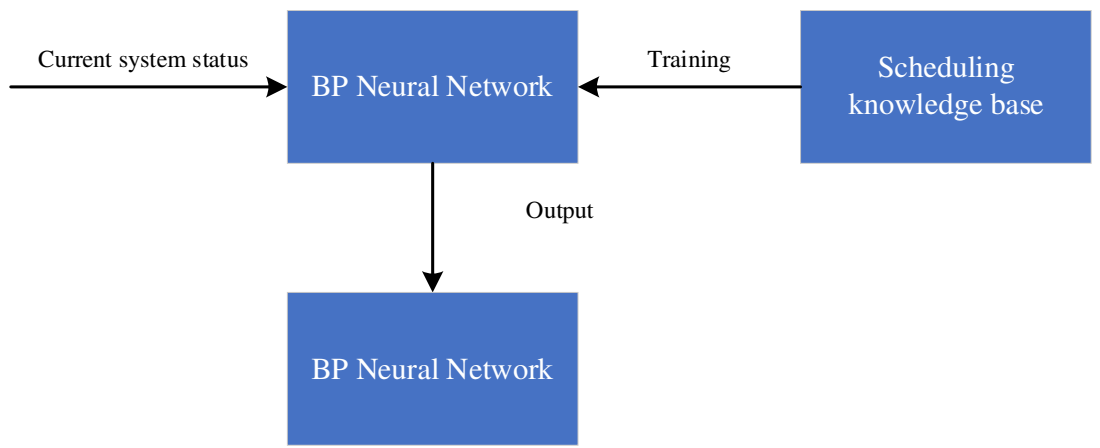

Figure. 4 Parameter estimation based on BP neural network

The ladle re-scheduling algorithm is divided into two parts: the re-scheduling algorithm and the ladle optimisation scheduling algorithm, which are described as follows.

\subsection{Re-scheduling algorithm \\ 5.1.1 Decision algorithm for rescheduling heat}


The re-scheduling objects are unfinished heat. Let $\Omega$ be the set of heat that need to be re-scheduled in the initial scheduling plan set $\Omega^{0}$. Then, the decision algorithm for rescheduling heat is as follows:

\section{Algorithm 1: Decision algorithm for re-scheduling heat}

Step 1: Obtain the initial scheduling plan set $\Omega^{0}$ and the processing state $\beta_{i, j, \varepsilon_{i j}}$ of the batches in $\Omega^{0} 0$ in the continuous casting process. Let the set of rescheduling batches $\Omega=\Phi$;

Step 2: Let $i=1$;

Step 3: Let $j=1$;

Step 4: If $\beta_{i, j, \varepsilon_{i j}}=0$, then $\Omega=\Omega+\left\{L_{i j}\right\}$;

Step 5: If $j=J_{i}$, then go to Step 6; else, $j=j+1$, go to Step 4;

Step 6: If $i=3$, then go to Step 7; else, $i=i+1$, go to Step 3;

Step 7: end, get $\Omega$.

\subsubsection{Decision-making algorithm for the heat processing equipment}

If the heat $L_{i j}$ is assigned to the equipment for processing, then the heat that may conflict with $L_{i j}$ on the equipment is recorded as $L_{i_{1}, j_{1}}$. Let $F_{m}$ be the conflict value of the operating time of the heat $L_{i j}$ and $t L_{i_{1}, j_{1}}$ on equipment $m$ :

$$
F_{m}=\operatorname{Max}\left\{x_{i j k}, x_{i_{1}, j_{1}, k_{1}}\right\}-\operatorname{Min}\left\{y_{i j k}, y_{i_{1}, j_{1}, k_{1}}\right\} \quad L_{i j}, L_{i_{1}, j_{1}} \in \Omega
$$

When $F_{m}>0$, heat $L_{i j}$ and $L_{i_{1}, j_{1}}$ have a time conflict o. The working time conflict value $F_{m}$ must be resolved by heat working time translation to ensure that no time conflict exists between different heat processed on the same equipment. The waiting time value generated after the conflict is resolved is exactly equal to $F_{m}$.

This study uses the heuristic method shown in Figure 5 to solve:

\section{Re-scheduling heats}

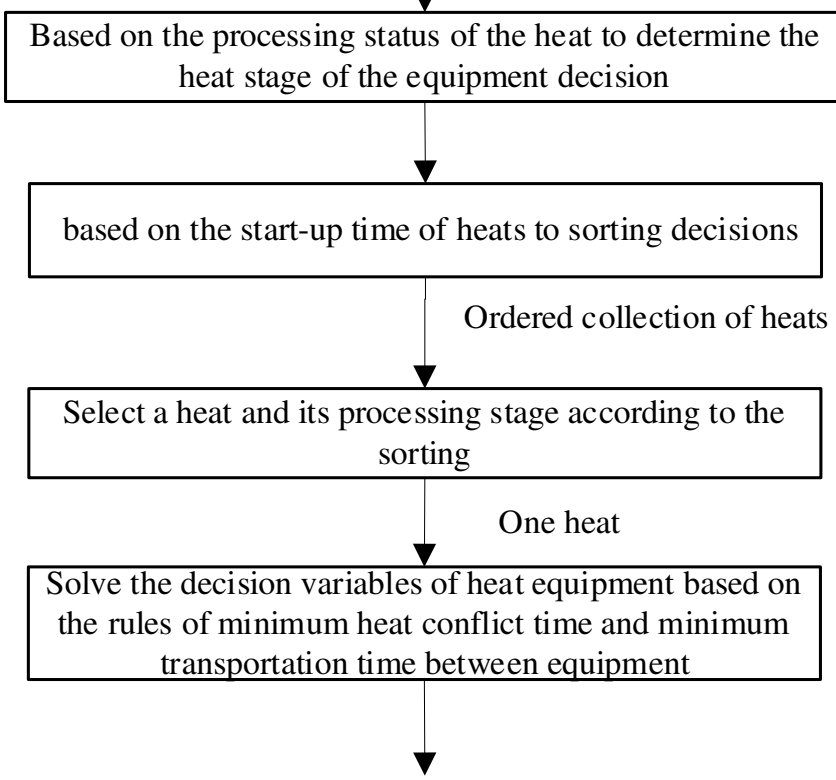

Figure. 5 Solving the decision variables of charge equipment

A Based on the processing status of the heat to determine the heat stage of the equipment decision

Let $\alpha_{i j k}$ be the variable of whether heat $L_{i j}$ can be adjusted in stage $k$ : if the equipment can be adjusted, then $\alpha_{i j k}=1$; otherwise, $\alpha_{i j k}=0$

(1) The processing equipment (continuous caster) of the heat in the continuous casting process has been designated, and it cannot be changed during the re-scheduling process.

$$
\alpha_{i, j, \varepsilon_{i j}}=0 \quad L_{i j} \in \Omega
$$

(2) When a heat is being processed or has been processed in a certain procedure, the re-scheduling can no longer change the processing equipment of the heat in that process:

$$
\alpha_{i j k}=0 L_{i j} \in \Omega ; k=1, \ldots, \varepsilon_{i j}-1 ; \beta_{i j k}=1,2
$$

(3) When the heat is not started in the non-continuous casting process, re-scheduling can adjust the processing equipment of the heat in the process; that is, when the heat $L_{i j}$ is in the stage $k\left(k \neq \varepsilon_{i j}\right)$, the processing state $\beta_{i j k}=0$. The re-scheduling method can reassign its equipment:

\section{$B$ Based on the start-up time of heat to sort decisions}

$$
\alpha_{i j k}=1 L_{i j} \in \Omega ; k=1, \ldots, \varepsilon_{i j}-1 ; \beta_{i j k}=0
$$


The heat in the rescheduled heat object set is divided into two batches, namely, processing and unstartled heat, denoted by $\Omega_{1}$ and $\Omega_{2}$.

The operations are processed or completed in batch $\Omega_{1}$ of the processing heat. The processing equipment and the start time of these operations in the process cannot be modified during re-scheduling. When adjusting the operating time of the unstartled operation in $\Omega_{1}$, the operating time can only be moved backward to meet the processing sequence constraints. Therefore, the operations are sequentially performed in the order of the start time of each operation in $\Omega_{1}$ from early to late. Let $O_{1}$ be the set of operations sorted by the start time of all operations in $\Omega_{1}$ from early to late.

In the batch of unstartled heat $\Omega_{2}$, the start time of the unstarted heat on the continuous caster should be the same as that of the previous heat processed on the same continuous caster due to the continuous casting constraints of adjacent heat in the same casting. The completion time is equal. Firstly, the start and completion times of the $\Omega_{2}$ heat on the continuous caster are calculated according to the completion time of $\Omega_{1}$ heat on the continuous caster. Then, the start and end times of the $\Omega_{2}$ heat in the refining and converter stages are calculated in reverse. Let $\mathrm{O}_{2}$ be the set of operations in which all operations of the $\Omega_{2}$ heat on the continuous caster are sorted from early to night. $O_{3}$ is all operations of the $\Omega_{2}$ heat in the refining and converter stages. The batching and operation sorting algorithm is as follows:

Algorithm 2: Heat batching and operation sorting algorithm

Step 1: Obtain the parameter information of the initial scheduling plan: the total number of cast $N$, the total number of heat of the $i$ th cast $J_{i}$, the completion time of the heat $L_{i j}$ on the continuous caster $e_{i, j, \varepsilon_{i j}}^{0}$ and re-

scheduling time $t_{r}$; then, determine the set of re-scheduling heat $\Omega$;

Step 2: Let $\Omega_{1}=\Phi, \Omega_{2}=\Phi, O_{1}=\Phi, O_{2}=\Phi, O_{3}=\Phi$;

Step 3: all heat $L_{i j} \in \Omega$ :

$$
\text { If } s_{i j 1}^{0} \leq t_{r} \text {, then } \Omega_{1}=\Omega_{1}+\left\{L_{i j}\right\} \text {; else, } \Omega_{2}=\Omega_{2}+\left\{L_{i j}\right\} \text {. }
$$

Step 4: In all heat $L_{i j} \in \Omega_{1}$ :
(a) Let $k=1$
(b) If $k<\varepsilon_{i j}+1$, then $O_{1}=O_{1}+\left\{o_{i j k}\right\}$;
(c) $k=k+1$, go to Step $4(b)$

Step 5: In all heat $L_{i j} \in \Omega_{2}$ :

$$
\begin{aligned}
& \text { (a) Let } k=1 \text {; } \\
& \text { (b) If } k<\varepsilon_{i j}+1 \text {; } \\
& \text { (c) If } k=\varepsilon_{i j} \text {, then } O_{2}=O_{2}+\left\{o_{i j k}\right\} \text {; else, } O_{3}=O_{3}+\left\{o_{i j k}\right\} \\
& \text { (d) } k=k+1 \text {, go to Step } 5(b) \text { 。 }
\end{aligned}
$$

Step 6: Arrange all operations in $O_{1}$ in an ascending order of start time.

Step 7: Arrange all operations in $\mathrm{O}_{2}$ in an ascending order of starting time.

Step 8: Arrange all operations in $\mathrm{O}_{3}$ in a descending order of starting time.

\section{$C$ Solve the decision variables based on the rules of minimum heat conflict time and minimum transportation time}

The calculation of heat equipment assignment variable is to select equipment in sequence according to the order of $\mathrm{O}_{1}+\mathrm{O}_{2}+\mathrm{O}_{3}$ to reduce the waiting time of heat between adjacent equipment. This study proposes a priority-based equipment assignment method: minimum conflict time between operations, minimum transportation time between equipment, minimum number of equipment processing furnaces and random selection.

(1) Minimum conflict time between operations

This study assumes the presence of operation $o_{i_{1}, j_{1}, k_{1}}$ on device $m$. When operation $o_{i j k}$ is also arranged on device $m, F_{m}>0, o_{i j k}$ and $o_{i_{1}, j_{1}, k_{1}}$ have a job conflict on device $m$. If $o_{i j k} \in O_{1}$, then $o_{i j k}$ is processed after $o_{i_{1}, j_{1}, k_{1}}$, as shown in Figure 6(a). Conflict time $\mathrm{F} F_{m}=Y_{i_{1}, j_{1}, k_{1}}-X_{i j k}$. At this time, only the operation time of $o_{i j k}$ can be shifted backward by $F_{m}$. If $o_{i j k} \in O_{3}$, and $o_{i_{1}, j_{1}, k_{1}} \in O_{3}$, then $o_{i j k}$ is processed before $o_{i_{1}, j_{1}, k_{1}}$, as shown in Figure 6(b); $F_{m}=Y_{i j k}-X_{i_{1}, j_{1}, k_{1}}$. At this time, the working time of $o_{i j k}$ is shifted forward by $F_{m}$. 


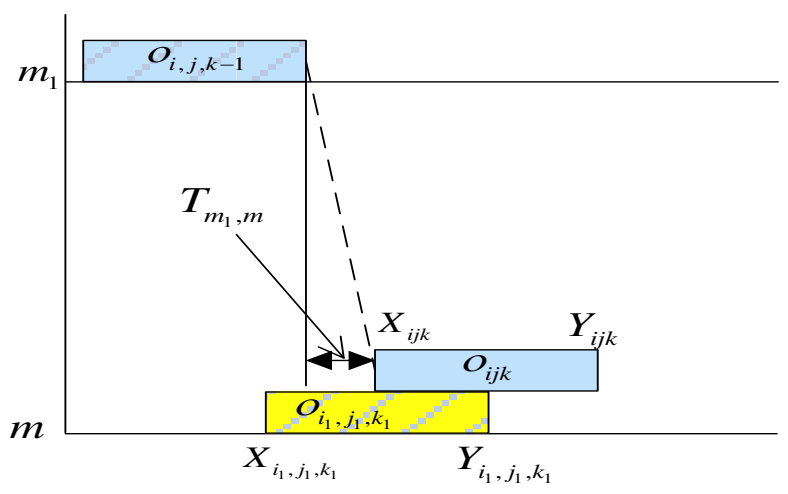

(a) $o_{i j k} \in O_{1}$

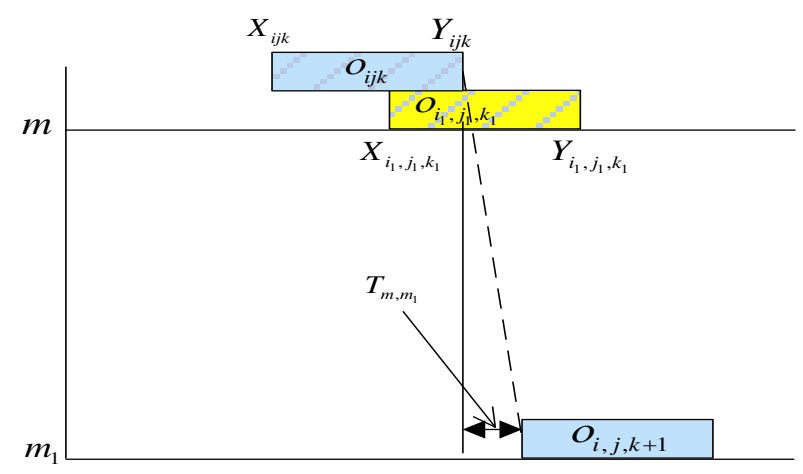

(b) $o_{i j k} \in O_{3}, o_{i_{1}, j_{1}, k_{1}} \in O_{3}$

Figure. 6 Operating conflict

When rescheduling, the minimum operating time conflict rule between operations is adopted. The equipment that minimises the operating time conflict is selected from the equipment set $\Pi_{\sigma_{i j k}^{0}}$ that can process $o_{i j k}$, namely:

(2) Shortest transportation time

$$
z_{i j k}^{m}=1 m=\operatorname{argmin}\left\{F_{m_{1}} \mid m_{1} \in \Pi_{\sigma_{i j k}^{0}}\right\}
$$

When re-dispatching, the minimum transportation time rule between equipment is adopted. The equipment with the shortest transportation time is selected from equipment set $\Pi_{\sigma_{i j k}^{0}}$ that can process $o_{i j k}$, namely:

(3) Minimum number of equipment

$$
z_{i j k}^{m}=1 m=\operatorname{argmin}\left\{T_{m_{1}, m_{2}} \mid m_{1} \in \Pi_{\sigma_{i j k}^{0}}\right\}
$$

The rule of the minimum number of equipment is adopted. The equipment with the least number of processing heat $H_{m}$ is selected from the equipment set $\Pi_{\sigma_{i j k}^{0}}$ that can be processed $o_{i j k}$, namely:

(4) Random selection

$$
z_{i j k}^{m}=1 m=\operatorname{argmin}\left\{H_{m_{1}} \mid m_{1} \in \Pi_{\sigma_{i j k}^{0}}\right\}
$$

The random selection rule refers to randomly selecting a device when assigning equipment to $o_{i j k}$, namely:

$$
z_{i j k}^{m}=1 m=\text { random }\left\{m_{1} \mid m_{1} \in \Pi_{\sigma_{i j k}^{0}}\right\}
$$

This study establishes the following equipment assignment based on rule priority: minimum conflict time rule, minimum transportation time rule, minimum number of processing heat and random selection rule. The $O_{1}$, $\mathrm{O}_{2}$ and $\mathrm{O}_{3}$ operating equipment assignment algorithms are described as follows:

Algorithm 3: $O_{1}$ operating equipment assignment algorithm

Step 1: Obtain an operation $o_{i j k}$ of the re-scheduling operation set $O_{1}$, the start time $s_{i j k}^{0}$ and completion time $e_{i j k}^{0}$ of the operation in the initial scheduling plan and the re-scheduling time $t_{r}$;

Step 2: If $k \neq \varepsilon_{i j}$, then go to Step 3; else, $z_{i j k}^{m_{i j k}^{0}}=1$, and go to Step 9.

Step 3: If $e_{i j k}^{0} \leq t_{r}$, or $s_{i j k}^{0} \leq t_{r}$ and $e_{i j k}^{0}>t_{r}$, then go to Step 4; else, go to Step 5 .

Step 4: $z_{i j k}^{m_{i j k}^{0}}=1, X_{i j k}=s_{i j k}^{0}, Y_{i j k}=e_{i j k}^{0}$, go to Step 10.

Step 5: Follow the minimum conflict time rule: 
(a) Calculate the start and end times of operation $o_{i j k}$ in all equipment: $X_{i j k}=Y_{i, j, k-1}+T_{m_{i, j, k-1}, m}, Y_{i j k}=$ $X_{i j k}+p_{i j k}^{B}\left(m \in \Pi_{\sigma_{i j k}^{0}}\right)$.

(b) Calculate $F_{m}\left(m \in \Pi_{\sigma_{i j k}^{0}}\right)$.

(c) Let $\Pi^{1}=\left\{\operatorname{argmin}\left\{F_{m} \mid m \in \Pi_{\sigma_{i j k}^{0}}\right\}\right\}$.

(d) If $\left|\Pi^{1}\right|=1$, that is, $\Pi^{1}$ has only one device, then select the device for operation $o_{i j k}$, and go to Step 9; else, go to Step 6.

Step 6: Use the shortest transportation time rule from $\Pi^{1}$ :

(a) Let $\Pi^{2}=\left\{\operatorname{argmin}\left\{T_{m_{i, j, k-1}, m} \mid m \in \Pi^{1}\right\}\right\}$

(b) If $\left|\Pi^{2}\right|=1$, that is, $\Pi^{2}$ has only one device, then select the device for operation $o_{i j k}$, and go to Step 9; else go to Step 7.

Step 7: Use the minimum number of equipment rule from $\Pi^{2}$ :

(a) Let $\Pi^{3}=\left\{\operatorname{argmin}\left\{H_{m} \mid m \in \Pi^{2}\right\}\right\}$.

(b) If $\left|\Pi^{3}\right|=1$, that is, $\Pi^{3}$ has only one device, then select the device for operation $o_{i j k}$, and go to Step 9 ; else, go to Step 8.

Step 8: When $z_{i j k}^{m}=1\left(m=\right.$ random $\left.\left\{m_{1} \mid m_{1} \in \Pi^{3}\right\}\right)$, go to Step 9 .

Step 9: $X_{i j k}=Y_{i, j, k-1}+T_{m_{i, j, k-1}, m_{i j k}}$, and $Y_{i j k}=X_{i j k}+p_{i j k}^{B}$.

Step 10: End.

Algorithm 4: $\mathrm{O}_{2}$ Operating equipment assignment algorithm

Step 1: Obtain an operation $o_{i j k}$ of the re-scheduling operating set $\mathrm{O}_{2}$;

Step 2: $z_{i j k}^{m_{i j k}^{0}}=1$;

Step 3: Calculate all the start and end times of operation $o_{i j k}: X_{i j k}=Y_{i, j-1, \varepsilon_{i, j-1}}$, and $Y_{i j k}=X_{i j k}+p_{i j k}^{B}$.

Step 4: End.

\section{Algorithm 5: $\boldsymbol{O}_{3}$ Operating equipment assignment algorithm}

Step 1: Obtain an operation $o_{i j k}$ of the re-scheduling operation set $O_{3}$;

Step 2: The shortest transportation time rule:

(a) Calculate the start and end times of operation $o_{i j k}$ in all equipment: $Y_{i j k}=X_{i, j, k+1}-T_{m, m_{i, j, k+1}}$, and $X_{i j k}=Y_{i j k}-p_{i j k}^{B}\left(m \in \Pi_{\sigma_{i j k}^{0}}\right)$.

(b) Calculate $F_{m}\left(m \in \Pi_{\sigma_{i j k}^{0}}\right)$.

(c) Let $\Pi^{1}=\left\{\operatorname{argmin}\left\{F_{m} \mid m \in \Pi_{\sigma_{i j k}^{0}}\right\}\right\}$.

(d) If $\left|\Pi^{1}\right|=1$, that is, $\Pi^{1}$ has only one device, then select the device for operation $o_{i j k}$, and go to Step 6 ; else, go to Step 3.

Step 3: Use the shortest transportation time rule from $\Pi^{1}$ :

(a) Let $\Pi^{2}=\left\{\operatorname{argmin}\left\{T_{m, m_{i, j, k+1}} \mid m \in \Pi^{1}\right\}\right\}$.

(b) If $\left|\Pi^{2}\right|=1$, that is, $\Pi^{2}$ has only one device, then select the device for operation $o_{i j k}$, and go to Step 6; else, go to Step 4.

Step 4: Use the minimum number of equipment rule from $\Pi^{2}$ :

(a) Let $\Pi^{3}=\left\{\operatorname{argmin}\left\{H_{m} \mid m \in \Pi^{2}\right\}\right\}$.

(b) If $\left|\Pi^{3}\right|=1$, that is, $\Pi^{3}$ has only one device, then select the device for operation $o_{i j k}$, and go to Step 6; else, go to Step 5.

Step 5: Randomly select a device from $\Pi^{3}: z_{i j k}^{m}=1\left(m=\right.$ random $\left.\left\{m_{1} \mid m_{1} \in \Pi^{3}\right\}\right)$, go to Step 6 .

Step 6: $Y_{i j k}=X_{i, j, k+1}-T_{m_{i j k}, m_{i, j, k+1}}$, and $X_{i j k}=Y_{i j k}-p_{i j k}^{B}$

Step 7: End.

5.2 Ladle matching rule extraction

\subsubsection{Minimal generalisation rule learning}

\section{A Minimal generalisation rule learning method}

The least generalisation (LGG) can directly use the specific facts corresponding to one or more positive examples as initial rules and then gradually generalise the rules to increase their coverage of the sample. The basic idea is as follows:

In a given first-order formula $r_{1}$ and $r_{2}$, LGG firstly finds the text of the same predicate and then examines the constant for each position in the text one by one. If the constant in the two words remains unchanged, then it is recorded as $L G G(s, t)=V$, and in the future, all the occurrence of $L G G(s, t)$ position with $V$ instead. LGG then ignores $r_{1}$ and $r_{2}$, without the text of the common predicate. If the minimum generalisation method contains a 
predicate that a formula does not have, then the general generalisation method cannot be specialised for that formula. In decarburisation, the ladle matching rule extraction set the for learning A. Relative Minimum Generalisation (RLGG) defines the initial rule of example $e$ as $e \leftarrow K$, where $K$ is the sum of all the atoms in the background. The corresponding decarburisation ladle matching Table 2 data are taken as an example. Let the initial rule be 'available $(1) \leftarrow$ (steel species $=$ AK202204 $) \wedge$ (refining path=LR) $\wedge \cdots \wedge$ (drainage material (West) $=$ forsterite $) \wedge($ empty ladle weight $=136)$ ', 'avail+able $(6) \leftarrow($ steel species $=$ XK437311 $) \wedge($ refining path=LR $) \wedge$ $\cdots \wedge($ drainage material $($ West $)=$ forsterite $)$ and available $(\mathrm{x}) \leftarrow($ steel species $=\mathrm{Y}) \wedge($ refining path=LR $) \wedge \cdots \wedge$ (drainage material $($ West $)=$ forsterite). In decarburisation ladle matching rule extraction set the method for learner B.

\section{B Evaluation and selection}

Decarburisation ladle rule extraction learning assessment and selection of the first choice of experimental evaluation methods are conducted. Then, evaluation learners should be present to measure the standard of generalisation, that is, performance metrics; Finally, a comparison test is also conducted to compare the performance of learners A and B. The steps shown in Figure 7.

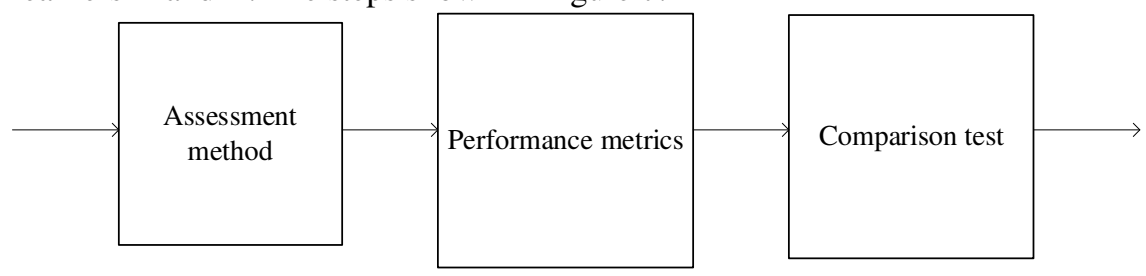

Figure. 7 Evaluation and selection

(1) Assessment method: In decarburisation ladle matching rule extraction, the method of leaving the assessment is adopted to avoid decarburisation ladle matching rules extracted through the training data to learn the ladle matching rules showing 'over-fitting' and 'under-fitting' phenomena. The decarburised ladle selection rules are extracted using random division, the test evaluation is repeated. Then, the average is taken as the outcome of the assessment results. This work selects $2 / 3$ of the data samples for rule extraction training. One third of the data samples are used to evaluate the test error.

(2) Performance metrics: In decalcification ladle matching rule extraction, the definition of the error rate is the number of misclassifications of the total sample size ratio. The accuracy is the correct number of samples classified the proportion of the total sample. In the decimation rules for decarburisation ladle extraction set $\mathrm{D}$, the classification error rate is defined as follows:

Accuracy is defined as:

$$
E(f ; D)=\frac{1}{m} \sum_{i=1}^{m} I I\left(f\left(x_{i}\right) \neq y_{i}\right)
$$

$$
\operatorname{acc}(f ; D)=\frac{1}{m} \sum_{i=1}^{m} I I\left(f\left(x_{i}\right)=y_{i}\right)=1-E(f ; D)
$$

In the ladle matching of these two classifications, the ladle matching test samples are classified into real cases, false positive cases, true negative cases and false negative cases according to the real category and the learner prediction category. Let TP, FP, TN and FN represent the corresponding sample number. Then, TP + FP $+\mathrm{TN}+\mathrm{FN}=$ total number of samples. The 'confusion matrix' of the classification results extracted by the decarburisation ladle matching rule is shown in Table 4:

Table 4 Classification result of confusion matrix

\begin{tabular}{c|c|c}
\hline \multirow{2}{*}{ True situation } & \multicolumn{2}{|c}{ Forecast result } \\
\cline { 2 - 3 } & $\begin{array}{c}\text { Positive } \\
\text { example }\end{array}$ & $\begin{array}{c}\text { Counter } \\
\text { example }\end{array}$ \\
\hline $\begin{array}{c}\text { Positive } \\
\text { example }\end{array}$ & $T P$ & $F N$ \\
\hline $\begin{array}{c}\text { Counter } \\
\text { example }\end{array}$ & $F P$ & $T N$ \\
\hline
\end{tabular}

Then, the accuracy rate $\mathrm{P}$ and recall rate $\mathrm{R}$ are defined as follows:

$$
\begin{gathered}
P=\frac{T P}{T P+F P} \\
R=\frac{T P}{T P+F N}
\end{gathered}
$$

The samples are sorted according to the learner's prediction of ladle selection, and the rules that learners consider 'most likely' to be positive are prescribed, followed by rules that learners consider 'least likely to be positive. The homeopathic rules are pressed one by one as a positive example to predict and calculate the current recall and accuracy rates. The 'equilibrium point' is defined for the rate of recall = recall rate value. The advantages and disadvantages of learners A and B can be compared on the basis of BEP. On this basis, LGG and RLGG are measured based on the definition:

$$
F_{\beta}=\frac{\left(1+\beta^{2}\right) \times P \times R}{\left(\beta^{2} \times P\right)+R}
$$


When $\beta=1$, the accuracy and recall rates are equally important; when $\beta>1$, the recall rate has a greater impact; when $\beta<1$, the accuracy rate has a greater impact. In decarbonisation ladle matching, high precision is important to ensure the safety of production. LGG and RLGG can meet the error rate, accuracy and precision requirements.

(3) Comparison test: These two classification problems are addressed in ladle matching. Using the set aside method can not only estimate the test error rate of learners A and B but also obtain the difference between the results of LGG and RLGG. Specifically, both are correct, all wrong, and one is the correct number of another wrong sample, as shown in Table 5.

Table 5 Contingency table of learner classification differences

\begin{tabular}{c|c|c}
\hline \multirow{2}{*}{ Algorithm B } & \multicolumn{2}{|c}{ Algorithm A } \\
\cline { 2 - 3 } & Ture & False \\
\hline Ture & $e_{00}$ & $e_{01}$ \\
False & $e_{10}$ & $e_{11}$ \\
\hline
\end{tabular}

This study assumes that LGG and RLGG identically behave, and $e_{01}=e_{10}$. Then, $\left|e_{01}-e_{10}\right|$ obeys the normal distribution, the mean is one, the variance is $e_{01}+e_{10}$.

$$
\tau_{\chi^{2}}=\frac{\left(\left|e_{01}-e_{10}\right|-1\right)^{2}}{e_{01}+e_{10}}
$$

The $\chi^{2}$ distribution with 1 degree of freedom is observed. Given a significance of $\alpha=0.05$, one cannot reject the assumption that no difference can be observed in LGG and RLGG performance when the above variable value is less than the threshold value $\chi_{\alpha}^{2}=3.8415$. Otherwise, the assumption that a significant difference exists between LGG and RLGG performance is rejected, and the average error rate of smaller learner performance worsens. The extraction rules for ladle selection involve additional test data to ensure that the learner learning results gradually change from underftting to overftting.

\subsubsection{Ladle selection rules}

\section{A Learner selection}

The decarburisation ladle matching rules are extracted using different data to learn. The test data are shown in Table 6.

Table $6 \tau_{\chi^{2}}$ value of learner

\begin{tabular}{c|c|c|c|c|c|c}
\hline \multirow{2}{*}{$\tau_{\chi^{2}}$} & \multicolumn{5}{|c}{ Test data volume } \\
\cline { 2 - 7 } & 120 & 240 & 360 & 600 & 1200 & 2400 \\
\hline $\mathrm{A}$ & 3.5310 & 4.4395 & 4.8323 & 4.1035 & 5.3536 & 5.3604 \\
$\mathrm{~B}$ & 3.2132 & 3.8531 & 4.1965 & 3.8542 & 5.1303 & 5.1743 \\
\hline
\end{tabular}

In Table 6, the deciphering ladle selection rules are applied to extract the amount of test data. The learning results gradually change from underfitting to overfitting. Learner B's performance is better, and RLGG is more suitable for optional decarburisation ladle when this method is used to obtain matching rules.

\section{B Selection rules for dephosphorisation ladle}

a) Only one online dephosphorisation ladle (R1)

Rule 1: Only one online dephosphorisation ladle

b) Two online dephosphorisation ladles (R2)

$$
\text { IF } N_{z}=1 \text { THEN } k_{1} \text { for } L_{i j}
$$

Rule 2.1: Two online dephosphorisation ladles are present, and the temperature varies

$$
\text { IF } N_{z}=2 \text { and } T\left(k_{1}\right)>T\left(k_{2}\right) \text { THEN } k_{1} \text { for } L_{i j}
$$

Rule 2.2: Two online dephosphorisation ladles are available, the temperature is the same, and the use time varies.

$$
\text { IF } N_{z}=2 \text { and } T\left(k_{1}\right)=T\left(k_{2}\right) \text { and } L\left(k_{1}\right)>L\left(k_{2}\right) \text { THEN } k_{1} \text { for } L_{i j}
$$

c) No online ladle is available, and a non-online ladle is available (R3).

Rule 3.1: No online ladle is available, and only one available non-online dephosphorisation ladle is present.

$$
\text { IF } N_{z}=0 \text { and } N_{f}=1 \text { THEN } k_{1} \text { for } L_{i j}
$$

Rule 3.2: No online ladle is available, and multiple non-online ladles are present, of which only one ladle has the highest temperature.

$$
\text { IF } N_{z}=0 \text { and } N_{f}>1 \text { and } T\left(k_{1}\right)>T\left(k_{2}\right) \text { THEN } k_{1} \text { for } L_{i j}
$$

Rule 3.3: No online ladle is available. Nevertheless, multiple off-line ladles are available. More than one ladle have the highest temperature, and only one ladle has the highest use time amongst the ladle with the highest temperature.

$$
\text { IF } N_{z}=0 \text { and } N_{f}>1 \text { and } T\left(k_{1}\right)=T\left(k_{2}\right) \text { and } L\left(k_{1}\right)>L\left(k_{2}\right) \text { THEN } k_{1} \text { for } L_{i j}
$$

d) No dephosphorisation ladle is available (R4)

Rule 4: No dephosphorisation ladle is available.

$$
\text { IF } N_{z}=0 \text { and } N_{f}=0 \text { THEN man-machine }
$$


where $N_{z}$ is the number of online dephosphorisation ladles that meet the constraints, $N_{f}$ is the number of non-online dephosphorisation ladles that meet the constraints, $L_{i j}$ is the amount of heat that currently need to be equipped with dephosphorisation ladles, $T(k)$ is the temperature of the ladle, and $L(k)$ is the life of the ladle;

Rule 5: Ladle selection weight

Each ladle can be expressed as a quaternion $\langle Z(k), T(k), L(k), k\rangle$, where $Z(k)$ is the remaining time of the ladle online ladle, $T(k)$ is the temperature of the ladle, $L(k)$ is the life of the ladle, and $\mathrm{k}$ is the serial number of the ladle. The total weight coefficient $W_{i}$ is defined as follows:

\section{Selection rules for decarburisation ladle}

$$
W_{i}=\alpha \cdot\langle Z(k)\rangle+\beta \cdot\langle T(k)\rangle+\gamma \cdot\langle L(k)\rangle+\delta \cdot\langle k\rangle
$$

In summary, the use of field data extraction rules and ladle matching rules are as follows.

Rule 1: Steel code

Steel has steel code beginning with KK or XK and needs the ladle whose life is less than 50 and a number of sinks greater than or equal to two and less than 10 .

$$
\text { IF } S k_{1,2}=K K \text { and } S k_{1,2}=X K \text { THEN } L(k)<50 \text { and } 2 \leq U_{e}^{k} / U_{w}^{k}<10
$$

Rule 2: The furnace contains LF refining.

Choose a ladle whose used time is not more than 15 and less than 100 .

$$
\text { IF LF THEN } U_{e}^{k} / U_{w}^{k} \leq 15 \text { and } L(k)<100
$$

Rule 3: The furnace is the first furnace of continuous casting.

The first furnace cannot use the new continuous casting ladle.

$$
\text { IF } j=1 \text { THEN } L_{i 1}(k) \neq 0
$$

Rule 4: Ladle material requirement

The material is divided into three $(M(k)=5$ or 6 or 7$)$; bale regulation first $R_{1}$ is the minimum material requirements.

$$
\text { IF } R_{1} \neq 0 \text { THEN } M(k) \geq R_{1}
$$

Rule 5: Steel on the new ladle or cold pack restriction

The second big bag regulation $R_{2}$ provides the new bag and cold bag requirements. $R_{2}=0$ means no rules; and $\mathrm{B}=1$ disables the new ladle.

$$
\text { IF } R_{2}=1 \text { THEN } L(k) \neq 0
$$

$R_{2}>1$ diables the new ladle and the cold ladle and selects the same ladle as the second ladle with the ladle status code.

Rule 6: ladle on a furnace restriction

$$
\text { IF } R_{2}>1 \text { THEN } L(k) \neq 0 \text { and } R_{2}=S_{2}^{k}
$$

The third bit of code $\mathrm{C}=0$ means no requirement on the previous furnace; otherwise, the ladle with the same status as the code is selected.

\subsubsection{Ladle optimal scheduling algorithm}

$$
\text { IF } R_{3} \neq 0 \text { THEN } R_{3}=S_{3}^{k}
$$

This study proposes a ladle optimal scheduling algorithm consisting of ladle selection and routing.

\section{Algorithm 6 Dephosphorisation ladle selection algorithm}

Step 1: The heat that need to be equipped with dephosphorisation ladle are sorted from early to late according to the dephosphorisation converter completion time $y_{i j 1}\left(k_{1}\right)$ and the dephosphorisation time set $\Phi=$ $\left\{L_{1}, L_{2}, \cdots, L_{N}\right\}$

Step 2: Initialise the state of all dephosphorisation ladle (ladle temperature $T(k)$, ladle used time $L(k)$ and ladle available time $t_{k}$ ); then, initialise $n=1$;

Step 3: Select a dephosphorisation ladle for the heat according to the corresponding rules;

a) Only one online ladle, optional dephosphorisation ladle according to R1;

b) Only two online ladles, optional dephosphorisation ladle according to R2;

c) No online ladle is present, but an off-line ladle is available. Dephosphorisation ladle is optional according to R3;

d) No online and off-line ladle are available. Dephosphorisation ladle is optional according to R4;

e) If multiple ladles are available, then select dephosphorisation ladle according to weight coefficient $W_{i}$;

Step 4: If $n=N$, then go to Step 5; else, $n=n+1$, and go to Step3;

Step 5: End.

\section{Algorithm 7 Decarburisation ladle selection algorithm}

Step1: The heat that need to be equipped with decarburisation ladle are sorted from early to late according to the decarburisation converter completion time $y_{i j 1}\left(k_{1}\right)$ and the decarburisation time set $\Phi=\left\{L_{1}, L_{2}, \cdots, L_{N}\right\}$;

Step 2: Initialise the state of all decarburisation ladle and $n=1$;

Step 3: Determine working conditions 1-6, and select the decarburisation ladle for the heat according to the corresponding rules 1-6;

Step 4: If $n=N$, then go to Step 5; else, $n=n+1$, and go to Step3; 
Step 5: End.

Algorithm 8 Ladle path compilation based on heuristic algorithm

Step 1: The initial heat set $\Phi$ is empty. Obtain all the heat and put them into the collection $\Phi$;

Step 2: Initialise the transportation interval set $\Psi$ to be empty, divide the transportation intervals for all heat, and put them into the set $\Psi$;

Step 3: Remove the transportation intervals in the set of transportation intervals $\Psi=\left\{\Psi_{1}, \Psi_{2}, \cdots, \Psi_{N}\right\}$ that have prepared routes;

Step 4: Sort the elements $\Psi_{i}$ in the set $\Psi=\left\{\Psi_{1}, \Psi_{2}, \cdots, \Psi_{N}\right\}$ in chronological order;

Step 5: Select the path for $\Psi_{i}$ according to the number of crane lifting times, the length of the path and the length of the transportation time;

Step 6: End.

\section{Application examples}

Based on the application analysis of a steelmaking plant in Shanghai China, the steelmaking plant often experienced delays in the start-up time of molten steel on the converter equipment, resulting in scheduling plans due to continuous casting breakout or furnace operating conflicts. At present, the factory scheduling is mainly based on manual adjustment. The selection of the adjustment method is based on manual experience simply by delaying the start time within $5 \mathrm{~min}$, between $5 \mathrm{~min}$ and $10 \mathrm{~min}$ and more than $10 \mathrm{~min}$ to classify the time: (1) When the delay is less than $5 \mathrm{~min}$, the scheduling plan will not be adjusted; (2) When the start time is delayed between $5 \mathrm{~min}$ and $10 \mathrm{~min}$, the processing start and end times are adjusted; (3) When the time delay is greater than $10 \mathrm{~min}$, the device is reselected. Manual adjustment leads to large fluctuations in production, which affects the production stability and continuity.

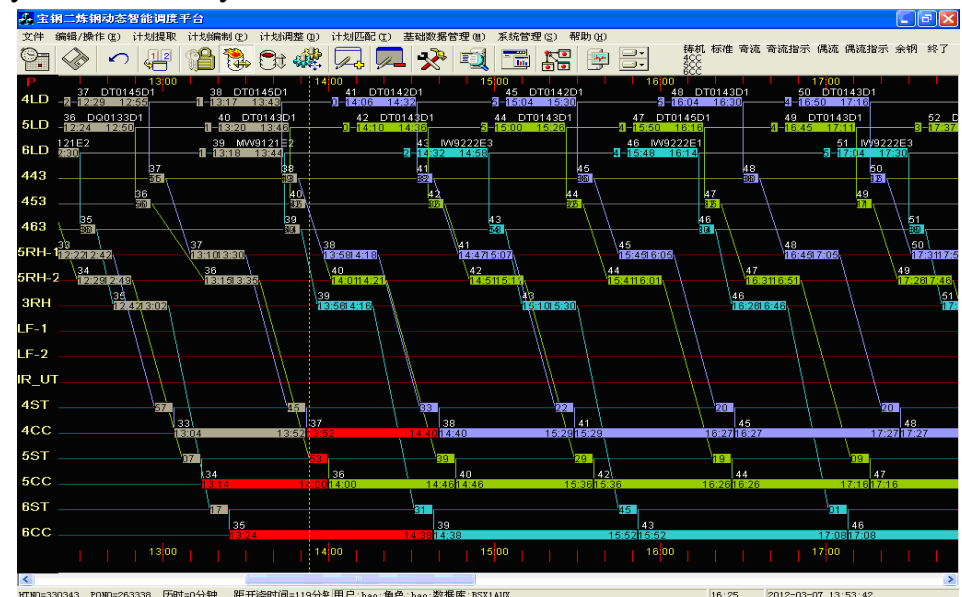

Figure. 8 Scheduling plan at time $t_{1}$

This study takes the actual steelmaking-continuous casting production ladle scheduling problem of this enterprise as an example to illustrate the application of this method and manual adjustment method. Figure 8 shows the pouring order information at time t1: $\Omega_{1}=\left\{L_{11}, L_{12}, L_{13}, L_{14}, L_{15}, L_{16}, L_{17}\right\}$, cast on 4CC; cast 2 on 5CC, $\Omega_{2}=\left\{L_{21}, L_{22}, L_{23}, L_{24}, L_{25}, L_{26}, L_{27}\right\}$; and cast 3 on $6 \mathrm{CC}, \Omega_{3}=\left\{L_{31}, L_{32}, L_{33}, L_{34}, L_{35}, L_{36}, L_{37}\right\}$. The processing time of the heat on the continuous caster is shown in Table 7.

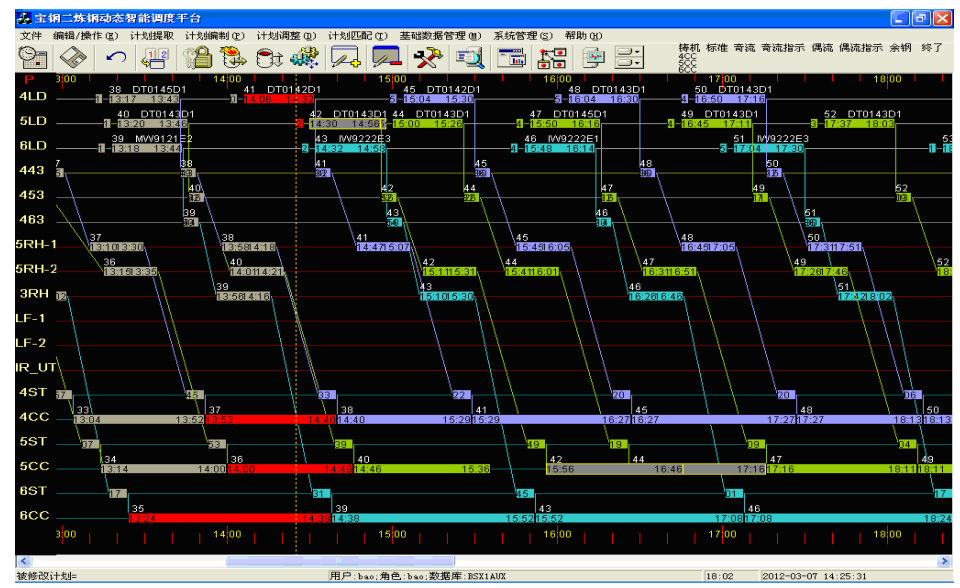

Figure. 9 Scheduling plan at time $t_{2}$ 
Table 7 Processing time on continuous castors

\begin{tabular}{|c|c|c|c|c|c|c|c|c|c|c|c|}
\hline Heat operation & $o_{113}$ & $o_{123}$ & $o_{133}$ & $o_{143}$ & $o_{153}$ & $o_{163}$ & $o_{173}$ & $o_{213}$ & $o_{223}$ & $o_{233}$ & $o_{243}$ \\
\hline $\begin{array}{l}\text { Minimum processing } \\
\text { time (minutes) }\end{array}$ & 45 & 45 & 45 & 50 & 55 & 45 & 40 & 45 & 45 & 50 & 45 \\
\hline $\begin{array}{l}\text { Standard processing } \\
\text { time (minutes) }\end{array}$ & 48 & 48 & 49 & 58 & 60 & 46 & 42 & 46 & 46 & 50 & 50 \\
\hline $\begin{array}{l}\text { Maximum processing } \\
\text { time (minutes) }\end{array}$ & 60 & 60 & 61 & 70 & 75 & 60 & 60 & 60 & 60 & 65 & 65 \\
\hline Heat operation & $O_{253}$ & $o_{263}$ & $o_{273}$ & $o_{283}$ & $o_{313}$ & $o_{323}$ & $o_{333}$ & $o_{343}$ & $o_{353}$ & $o_{363}$ & \\
\hline $\begin{array}{l}\text { Minimum processing } \\
\text { time (minutes) }\end{array}$ & 45 & 50 & 45 & 45 & 60 & 60 & 60 & 60 & 60 & 60 & \\
\hline $\begin{array}{l}\text { Standard processing } \\
\text { time (minutes) }\end{array}$ & 50 & 55 & 52 & 54 & 74 & 74 & 76 & 76 & 76 & 77 & \\
\hline $\begin{array}{l}\text { Maximum processing } \\
\text { time (minutes) }\end{array}$ & 65 & 70 & 67 & 70 & 85 & 85 & 85 & 85 & 85 & 85 & \\
\hline
\end{tabular}

In figure 9, the operation of heat $L_{24}$ on the converter 5LD $o_{241}$ starts processing, that is, $s_{241}^{*}=14: 21$. According to the scheduling plan at $T_{2}\left(T_{2}=14: 21\right)$, the correspondence between nodes and heat operations is shown in Table 8.

Table 8 Correspondence between nodes and operations

\begin{tabular}{|c|c|c|c|c|c|c|c|c|c|c|c|c|c|c|c|c|c|c|}
\hline Node & 1 & 2 & 3 & 4 & 5 & 6 & 7 & 8 & 9 & 10 & 11 & 12 & 13 & 14 & 15 & 16 & 17 & 18 \\
\hline $\begin{array}{c}\text { Operati } \\
\text { on }\end{array}$ & $o_{151}$ & $\kappa_{161}^{151}$ & $o_{161}$ & $\kappa_{171}^{161}$ & $o_{171}$ & $o_{241}$ & $\kappa_{251}^{241}$ & $o_{251}$ & $\kappa_{261}^{251}$ & $o_{261}$ & $\kappa_{271}^{261}$ & $o_{271}$ & $\kappa_{281}^{271}$ & $o_{281}$ & $o_{331}$ & $\kappa_{341}^{331}$ & $o_{341}$ & $\kappa_{351}^{341}$ \\
\hline Node & 19 & 20 & 21 & 22 & 23 & 24 & 25 & 26 & 27 & 28 & 29 & 30 & 31 & 32 & 33 & 34 & 35 & 36 \\
\hline $\begin{array}{c}\text { Operati } \\
\text { on }\end{array}$ & $o_{351}$ & $\kappa_{361}^{351}$ & $o_{361}$ & $\mu_{152}^{151}$ & $\mu_{162}^{161}$ & $\mu_{172}^{171}$ & $\mu_{242}^{241}$ & $\mu_{252}^{251}$ & $\mu_{262}^{261}$ & $\mu_{272}^{271}$ & $\mu_{282}^{281}$ & $\mu_{332}^{331}$ & $\mu_{342}^{341}$ & $\mu_{352}^{351}$ & $\mu_{362}^{361}$ & $o_{142}$ & $\kappa_{152}^{142}$ & $o_{152}$ \\
\hline Node & 37 & 38 & 39 & 40 & 41 & 42 & 43 & 44 & 45 & 46 & 47 & 48 & 49 & 50 & 51 & 52 & 53 & 54 \\
\hline $\begin{array}{l}\text { Operati } \\
\text { on }\end{array}$ & $\kappa_{162}^{152}$ & $o_{162}$ & $\kappa_{172}^{162}$ & $o_{172}$ & $o_{242}$ & $\kappa_{252}^{242}$ & $o_{252}$ & $\kappa_{262}^{252}$ & $o_{262}$ & $\kappa_{272}^{262}$ & $o_{272}$ & $\kappa_{282}^{272}$ & $o_{282}$ & $o_{332}$ & $\kappa_{342}^{332}$ & $o_{342}$ & $\kappa_{352}^{342}$ & $o_{352}$ \\
\hline Node & 55 & 56 & 57 & 58 & 59 & 60 & 61 & 62 & 63 & 64 & 65 & 66 & 67 & 68 & 69 & 70 & 71 & 72 \\
\hline $\begin{array}{c}\text { Operati } \\
\text { on }\end{array}$ & $\kappa_{362}^{352}$ & $o_{362}$ & $\mu_{143}^{142}$ & $\mu_{153}^{152}$ & $\mu_{163}^{162}$ & $\mu_{173}^{172}$ & $\mu_{243}^{242}$ & $\mu_{253}^{252}$ & $\mu_{263}^{262}$ & $\mu_{273}^{272}$ & $\mu_{283}^{282}$ & $\mu_{333}^{332}$ & $\mu_{343}^{342}$ & $\mu_{353}^{352}$ & $\mu_{363}^{362}$ & $o_{133}$ & $o_{143}$ & $o_{153}$ \\
\hline Node & 73 & 74 & 75 & 76 & 77 & 78 & 79 & 80 & 81 & 82 & 83 & 84 & 85 & & & & & \\
\hline $\begin{array}{c}\text { Operati } \\
\text { on }\end{array}$ & $o_{163}$ & $o_{173}$ & $o_{233}$ & $O_{243}$ & $o_{253}$ & $o_{263}$ & $o_{273}$ & $o_{283}$ & $o_{323}$ & $o_{333}$ & $o_{343}$ & $o_{353}$ & $o_{363}$ & & & & & \\
\hline
\end{tabular}

The identification results are obtained by analysing the extent to which the delay time affects the scheduling plan: (1) The breakouts of the caster in heat $L_{23}$ and $L_{24}$ can be simultaneously solved by adjusting the operating time. (2) Heat $L_{24}$ and $L_{25}$ have a heat operation conflict on the converter equipment. The operating conflict can be simultaneously resolved by adjusting the operation time of heat $L_{24}$ and $L_{25}$ on the converter equipment. (3) The operating conflict between heat $L_{24}$ and $L_{25}$ on the continuous caster can be simultaneously resolved by adjusting the operation time of heat $L_{24}$ and $L_{25}$ on the converter, refining furnace or continuous caster. According to the on-site manual scheduling method, all heat operating adjustments in the scheduling plan will include the reselection of processing equipment and the adjustment of the processing start and end times of the heat operation. The method in this study can solve this problem by adjusting the operating time of some heat; it ensures the continuity and stability of the scheduling plan and is beneficial to the stable and smooth production.

According to statistics, the average time for preparing a ladle scheduling plan compared with on-site manual ladle scheduling using the method proposed in this work is $3.4 \mathrm{~s}$, which is far less than the average manual preparation time of $30 \mathrm{~s}$. The number of online ladles is reduced from 23 to 19 , and the number of daily ladle maintenance is reduced from 17 times to 12 times. The time hit rate of heat (the proportion of heat that is strictly processed according to the plan) has been increased from $61 \%$ to $65 \%$ compared with manual preparation. The selection method proposed in this study can smoothen the steelmaking-refining-continuous casting production.

\section{Conclusion}

In steelmaking and continuous casting production processes, the starting time delay frequently occurs, which may lead to casting break or processing conflict. In view of the low efficiency of the current manual-made ladle scheduling, the manual selection of ladle will cause waste of resources and easily lead to excessive redundancy in steelmaking-continuous casting production. This work comprehensively considers the process constraints and the limitation factors to research the ladle re-scheduling problem. In comparison with previous studies, this work simultaneously considers the steelmaking-continuous casting production equipment scheduling problem and the 
ladle selection problem. Moreover, this work proposes a ladle re-scheduling method, which can effectively avoid the impact of disturbances in production.

Industrial verification was carried out based on the actual data from a large steel company in Shanghai, China. The ladle re-scheduling method proposed in this work can meet the requirements of the process for the ladle and reduce the production delay caused by unreasonable scheduling. Results showed that the production efficiency of steelmaking-refining-continuous casting was improved. The production efficiency and the economic benefits of the enterprise are improved compared with the previous manual establishment of on-site dispatchers.

\section{Acknowledgements}

This work was partly supported by the National Natural Science Foundation of China (61773269), the Natural Science Foundation of Liaoning Province of China (2019-BS-173, 2019-KF-03-08), the Program for Liaoning Excellent Talents in University (LR2019045), the Program for Shenyang High Level Innovative Talents (RC190042), National Natural Science Foundation of China (61873174), and Liaoning Provincial Natural Science Foundation of China (2020-KF-11-07).

\section{References}

[1] Xu W, Tang L, Pistikopoulos E N (2018). Modeling and solution for steelmaking scheduling with batching decisions and energy constraints. Computers \& Chemical Engineering, 116: 368-384.

[2] Cui H, Luo X (2017). An improved Lagrangian relaxation approach to scheduling steelmaking-continuous casting process. Computers \& Chemical Engineering, 106: 133-146.

[3] Brambilla C, Lavista F (2020). Privatizations and efficiency. Evidences from the Italian iron and steel industry, 1979-2016. Industrial and Corporate Change, 29(3): 757-778.

[4] Dong H, Liu Y, Wang L, et al (2019). Roadmap of China steel industry in the past 70 years. Ironmaking \& Steelmaking, 46(10): 922-927.

[5] Jiang S, Zheng Z, Liu M. A multi-stage dynamic soft scheduling algorithm for the uncertain steelmakingcontinuous casting scheduling problem. Applied Soft Computing, 2017, 60: 722-736.

[6] Wei, Z., Zhu, T., He, T., \& Liu, S. (2014). A fast heuristic algorithm for ladle scheduling based on vehicle routing problem with time windows model. ISIJ International, 54(11), 2588-2597.

[7] Jiang S L, Zheng Z, Liu M (2018). A preference-inspired multi-objective soft scheduling algorithm for the practical steelmaking-continuous casting production. Computers \& Industrial Engineering, 115: 582-594.

[8] Sun, L. L., \& Wang, X. Y. (2013). Application of mix optimization scheduling approach for steelmakingcontinuous casting process based on actual steelmaking industry. Journal of Iron and Steel Research International, 20(10), 1-9.

[9] Fanti, M. P., Rotunno, G., Stecco, G., Ukovich, W., \& Mininel, S. (2015). An integrated system for production scheduling in steelmaking and casting plants. IEEE Transactions on Automation Science and Engineering, 13(2), 1112-1128.

[10] Han, D., Tang, Q., Zhang, Z., \& Cao, J. (2020). Energy-Efficient Integration Optimization of Production Scheduling and Ladle Dispatching in Steelmaking Plants. IEEE Access, 8, 176170-176187.

[11] Liu, W., Pang, X. F., \& Chai, T. Y. (2019). Research on the dephosphorization ladle scheduling algorithm of steelmaking-refining-continuous casting process. Control Eng China, 26(4), 790.

[12] Li, J., Xu, A., \& Zang, X. (2020). Simulation-based solution for a dynamic multi-crane-scheduling problem in a steelmaking shop. International Journal of Production Research, 58(22), 6970-6984.

[13] Long, J., Zheng, Z., Gao, X., \& Pardalos, P. M. (2018). Scheduling a realistic hybrid flow shop with stage skipping and adjustable processing time in steel plants. Applied Soft Computing, 64, 536-549.

[14] Jiang, S. L., Zheng, Z., \& Liu, M. (2017). A multi-stage dynamic soft scheduling algorithm for the uncertain steelmaking-continuous casting scheduling problem. Applied Soft Computing, 60, 722-736. 
Figures

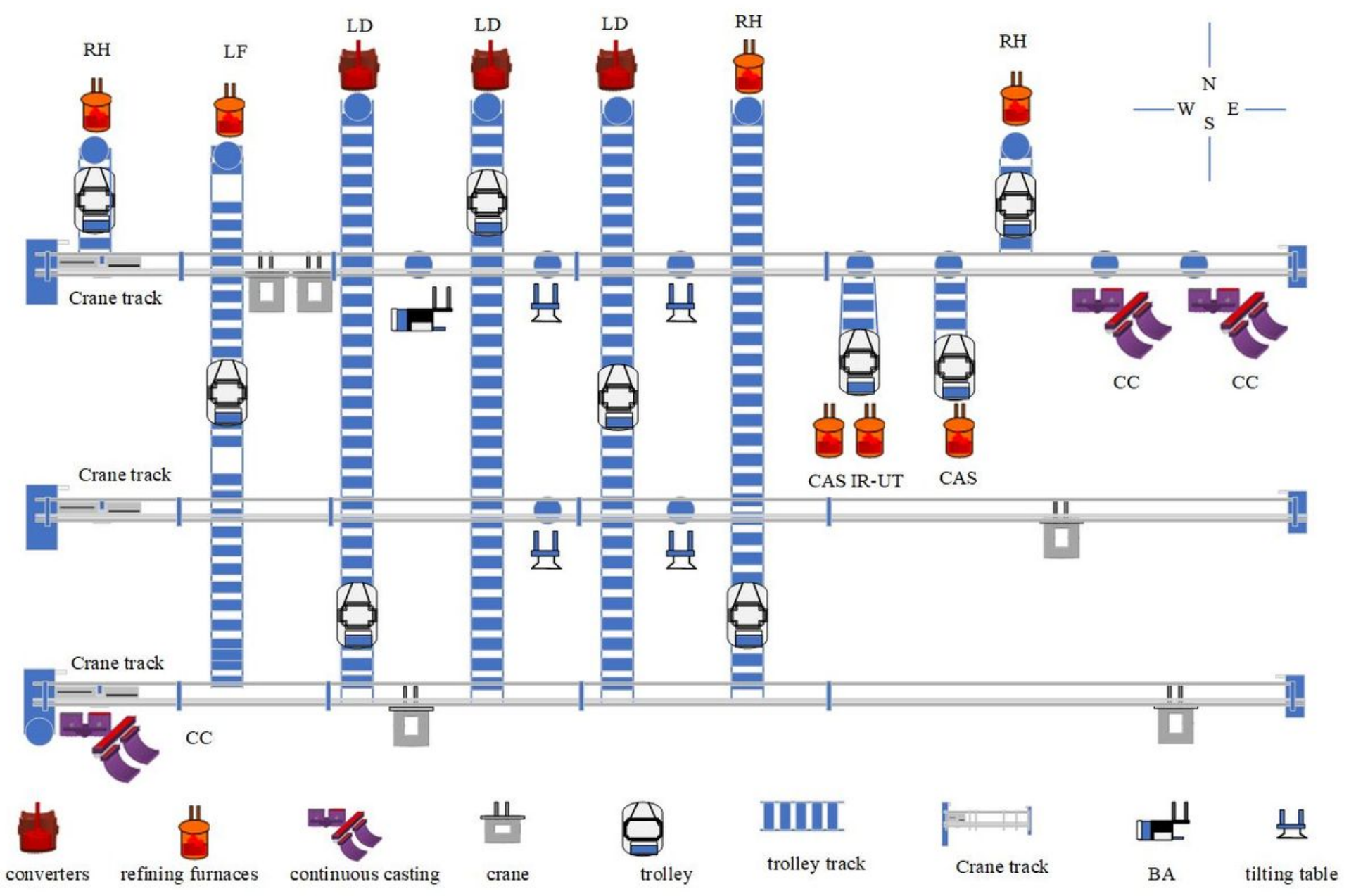

Figure 1

Layout of the steelmaking plant 


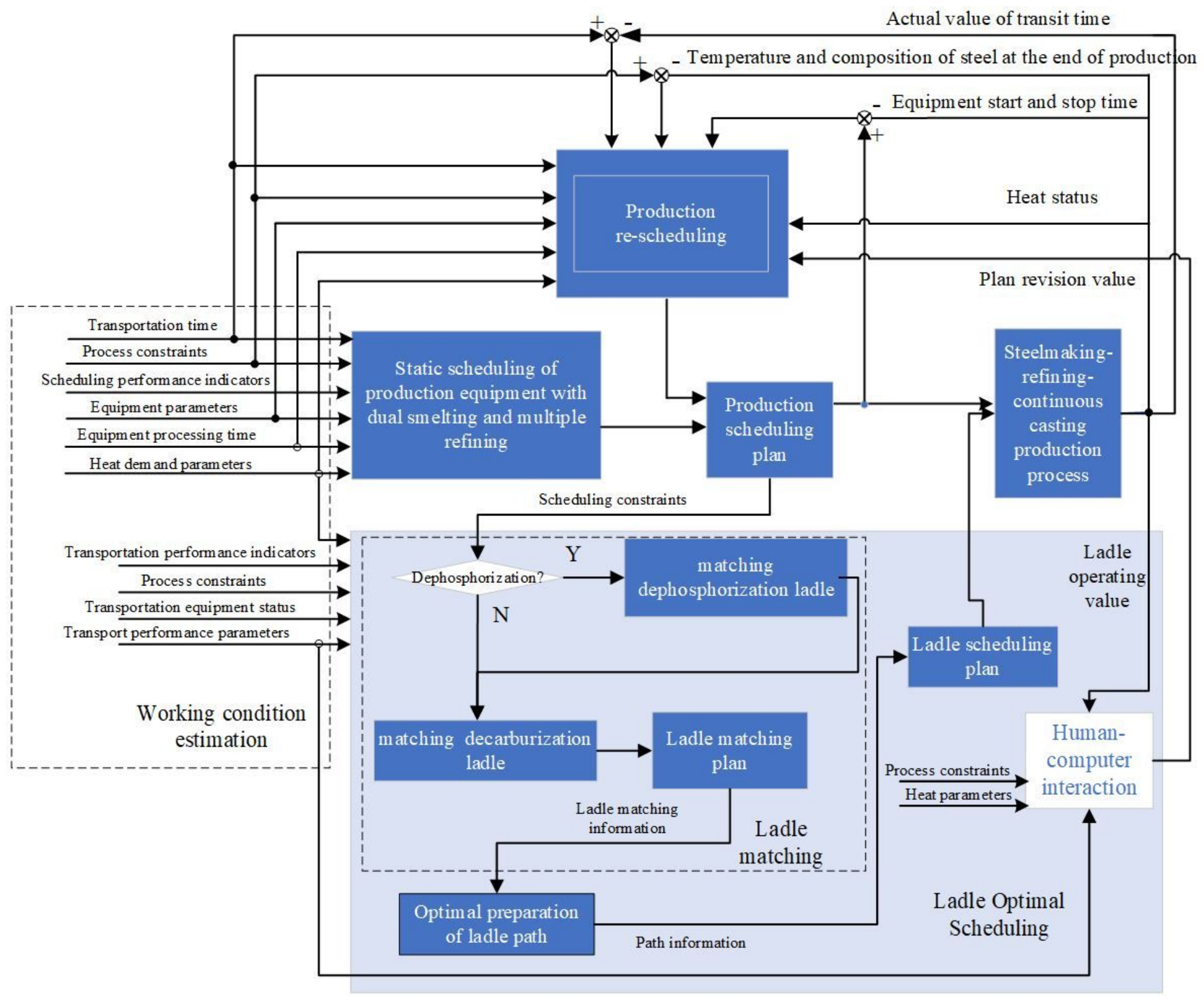

Figure 2

Steelmaking-refining-continuous casting overall scheduling strategy diagram 


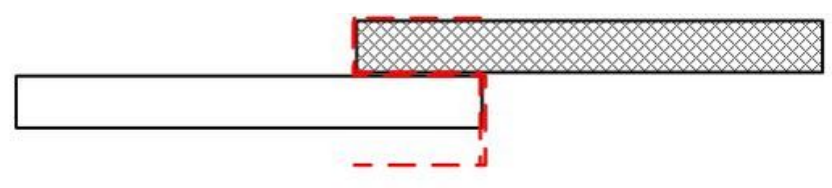

(a) Front cross conflict

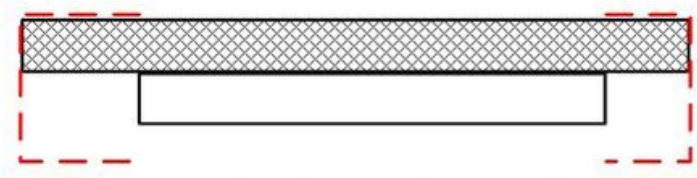

(c) Contain conflict

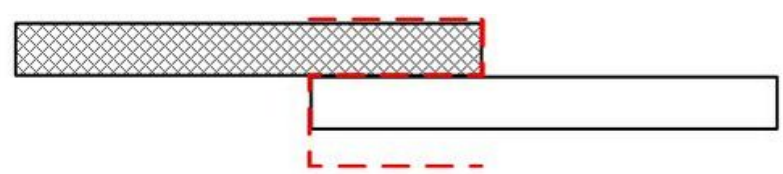

(b) Post-cross conflict

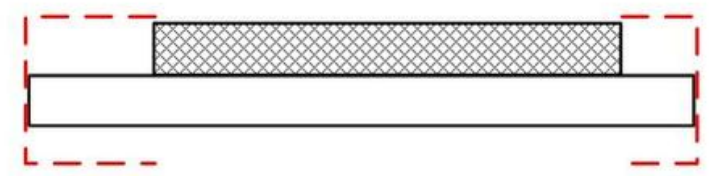

(d) Outside containing conflict

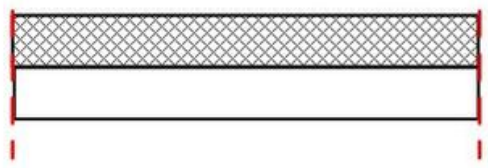

(e) Complete conflict

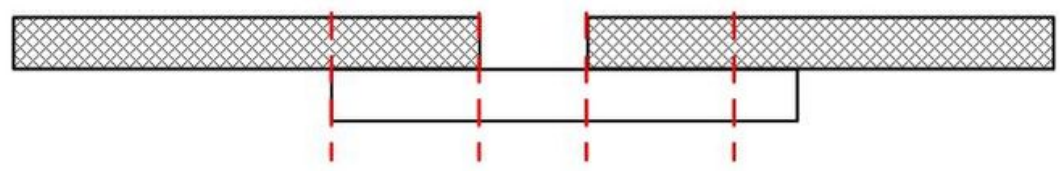

(f) Mixed conflict

newly-arranged heat $\square$ scheduled heat

\section{Figure 3}

Classification of time conflict amongst charges
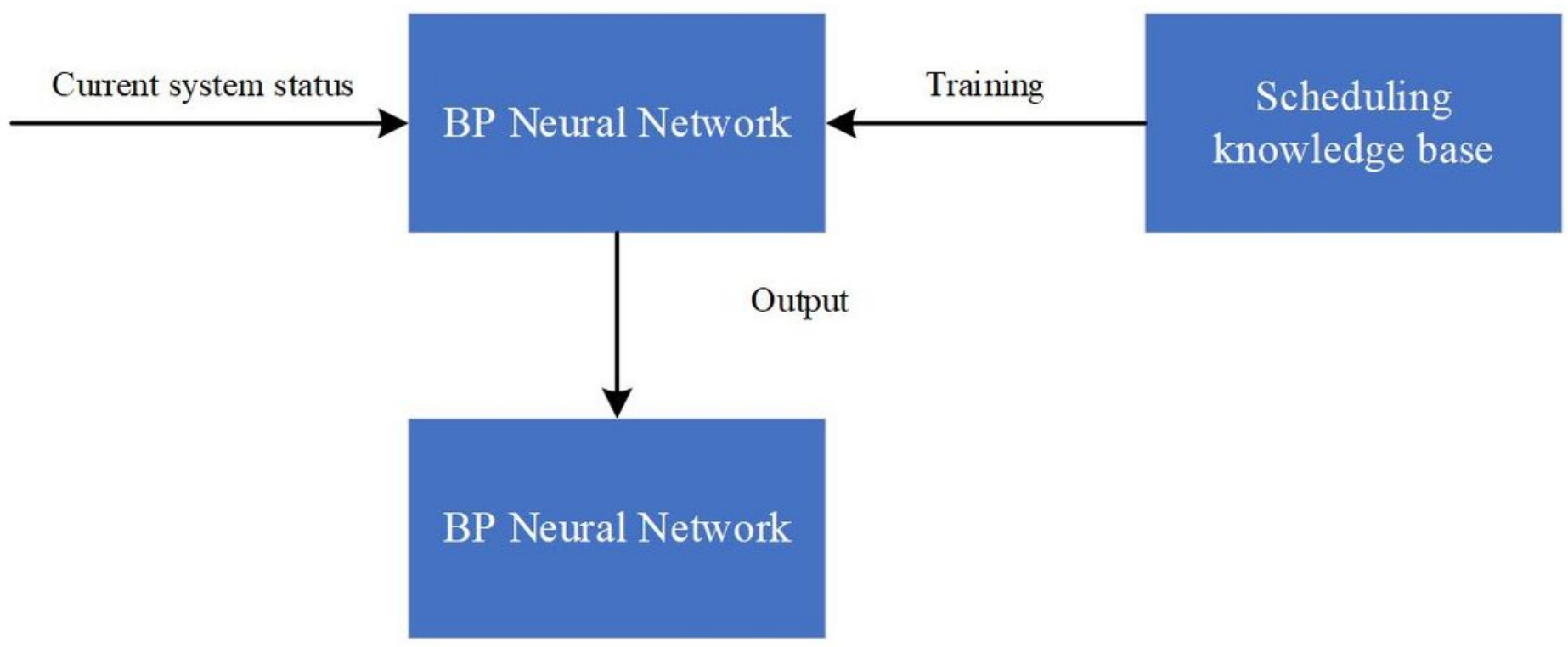

Figure 4

Parameter estimation based on BP neural network 


\section{Re-scheduling heats}

Based on the processing status of the heat to determine the heat stage of the equipment decision

based on the start-up time of heats to sorting decisions

Select a heat and its processing stage according to the sorting

\section{One heat}

Solve the decision variables of heat equipment based on the rules of minimum heat conflict time and minimum transportation time between equipment

Figure 5

Solving the decision variables of charge equipment 

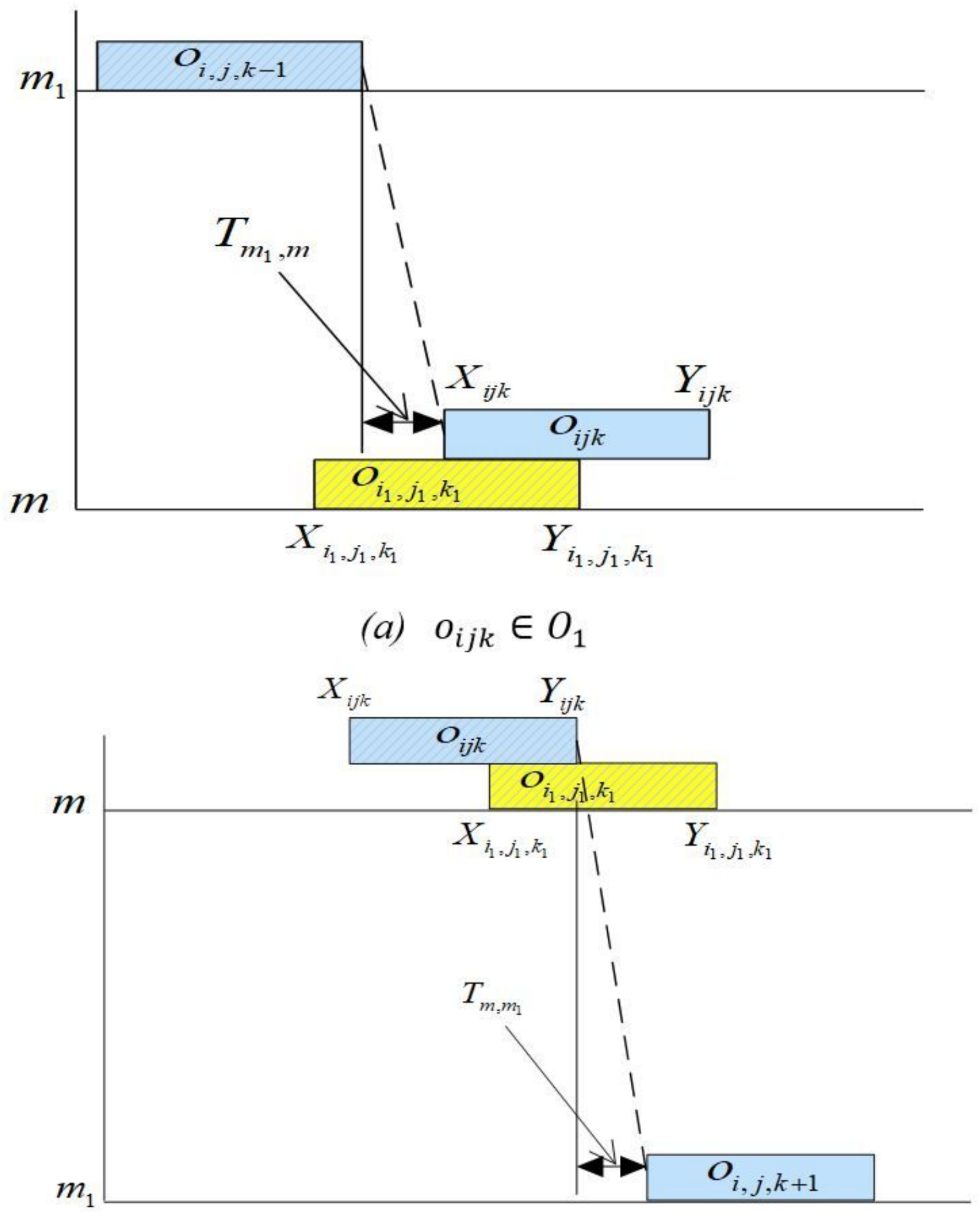

(b) $o_{i j k} \in O_{3}, o_{i_{1}, j_{1}, k_{1}} \in O_{3}$

Figure 6

Operating conflict 


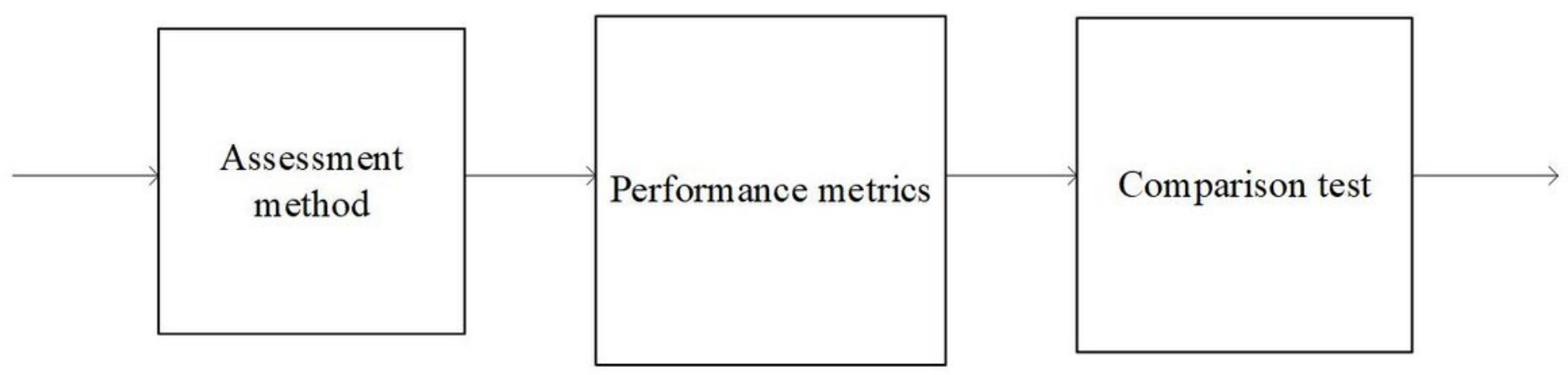

\section{Figure 7}

\section{Evaluation and selection}

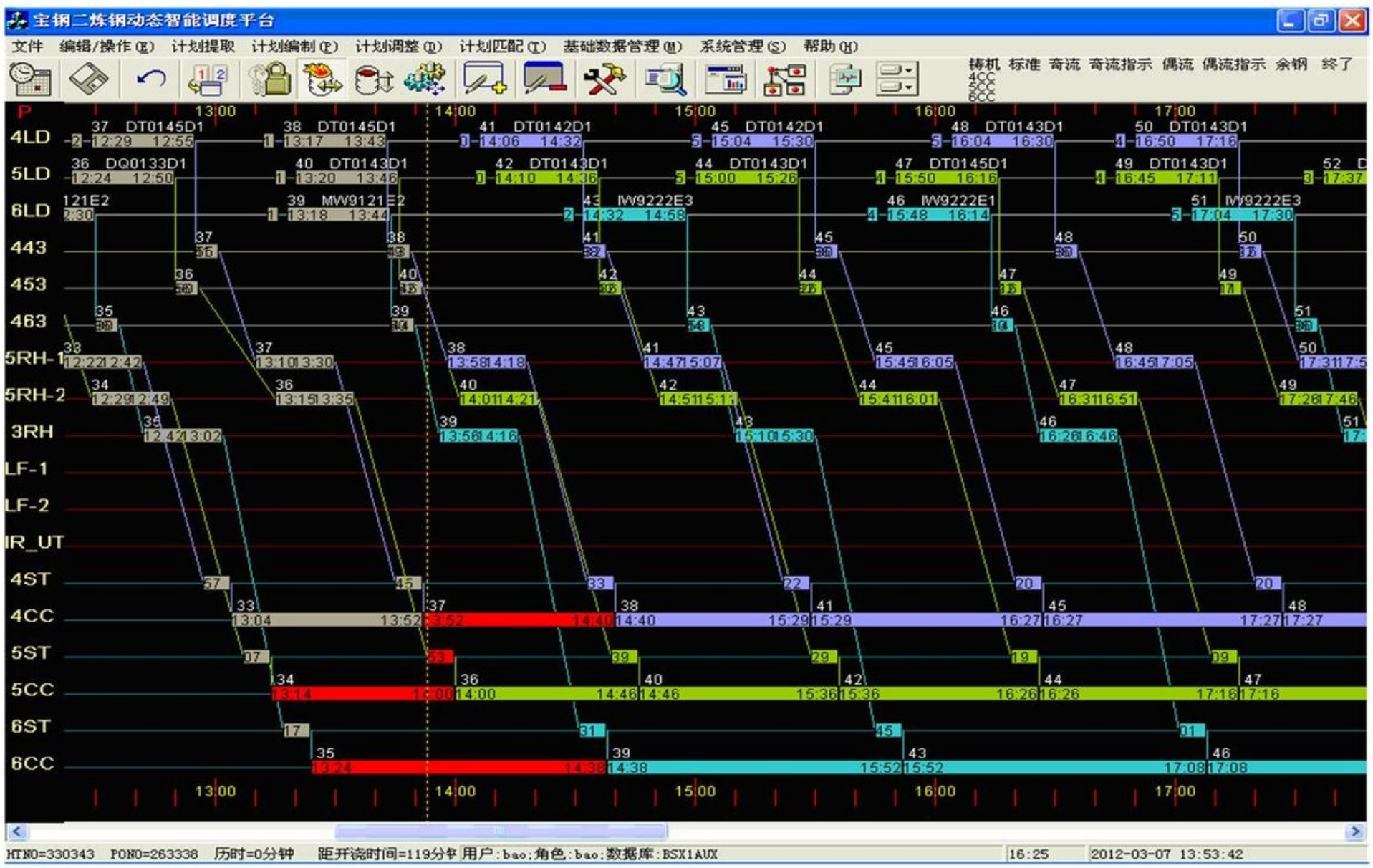

\section{Figure 8}

Scheduling plan at time t1 


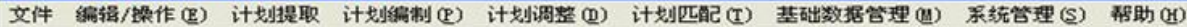

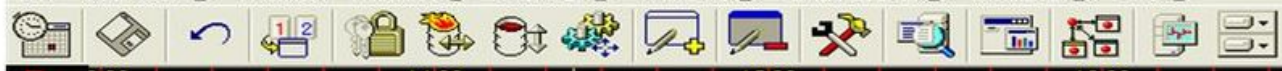

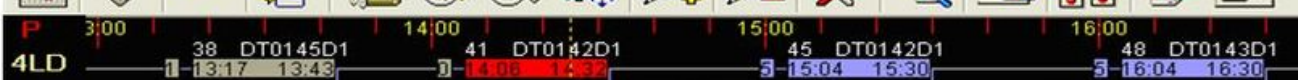

铸机 标准 奇流 奇流指示 偶流 偶流指示 余钢 终了

5LD $-10-13: 20$ DT0143D1 $13: 46$

42 DT014301 44 DTO14301 5

6LD $14: 30 \quad 14: 56:-\frac{14}{15: 00} 15: 26$

39 MW9121
$-13: 18 \quad 13: 44$

$443 \frac{7}{5}$

453

463

$5 \mathrm{RH}-1$ 13:103:30,

5RH-2 $\frac{36}{13: 1513: 35}$

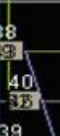

$43 \quad \mathrm{Wv}_{2222 \mathrm{E}}$

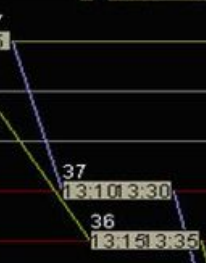

उRH 12

LF-1

$\mathrm{LF}-2$

IR_UT

4ST $\frac{1}{7}$

$4 \mathrm{CC} \frac{\sqrt{33 !}}{13: 0}$ 4

5ST $\quad 07$

$5 \mathrm{CC}$

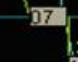

然

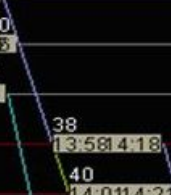

1.4:011:4:21 39

6ST 17

6CC

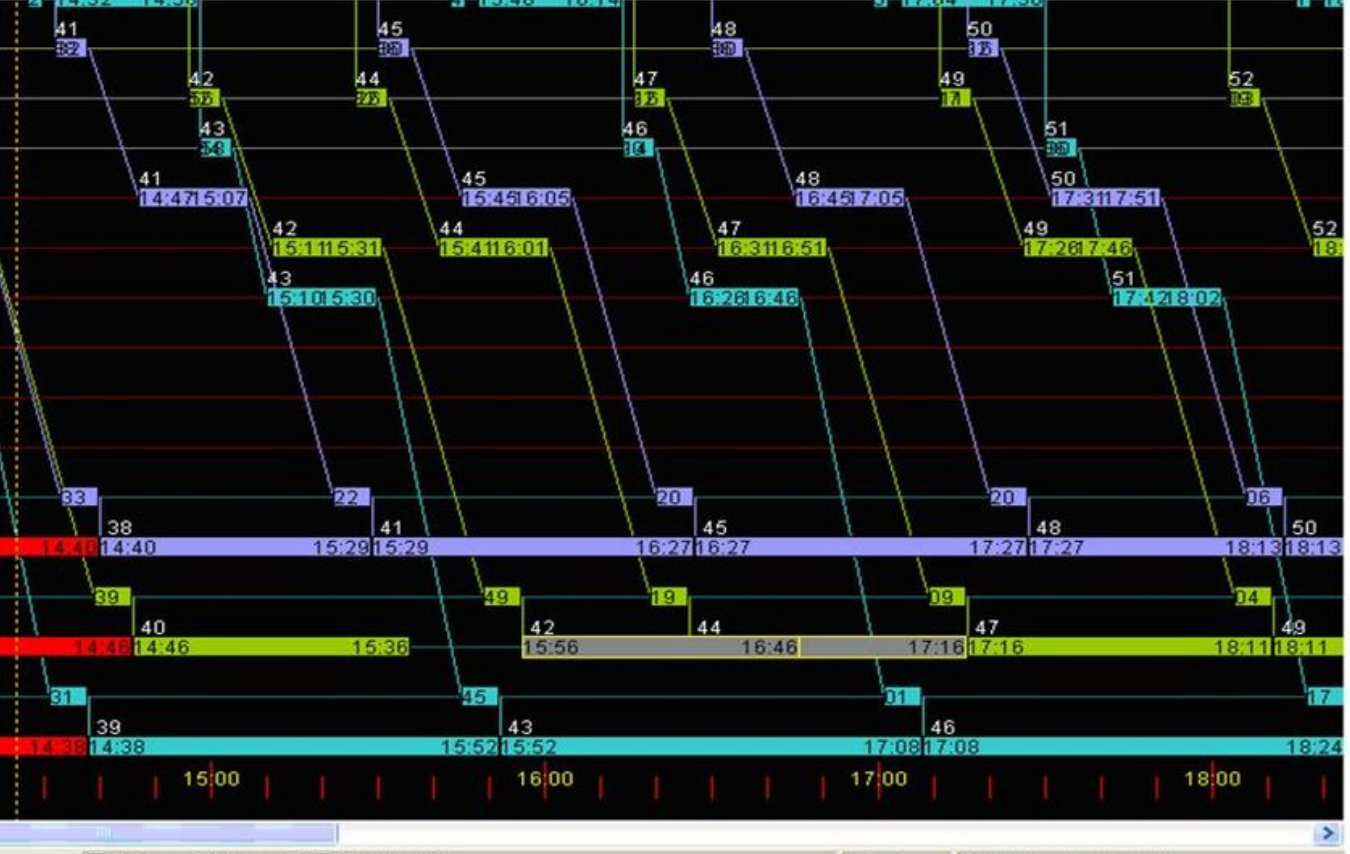
$-15: 50 \quad 16501$ 50 DT0143D1
$-4-16: 50 \quad 17: 16$ DT0143D1

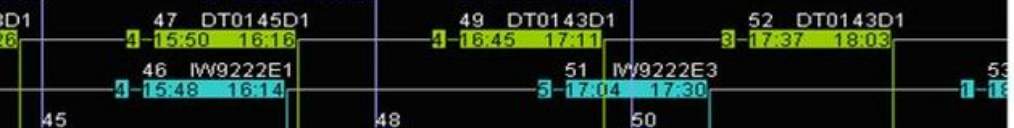
$<$

被攸改计划=

\section{Figure 9}

Scheduling plan at time t2 